\title{
Health-related Quality of Life and Pain in a Real-world Castration-resistant Prostate Cancer Population: Results From the PRO-CAPRI Study in the Netherlands
}

Malou C.P. Kuppen, ${ }^{1}$ Hans M. Westgeest, ${ }^{2}$ Alphonsus J.M. van den Eertwegh, ${ }^{3}$ Jules L.L.M. Coenen, ${ }^{4}$ Reindert J.A. van Moorselaar, ${ }^{5}$ Pieter van den Berg, Maud M. Geenen, ${ }^{7}$ Niven Mehra, ${ }^{8}$ Mathijs P. Hendriks, ${ }^{9}$ Menuhin I. Lampe, ${ }^{10}$ Addy C.M. van de Luijtgaarden, ${ }^{11}$ Frank P.J. Peters, ${ }^{12}$ Ton A. Roeleveld, ${ }^{13}$ Tineke J. Smilde, ${ }^{14}$ Ronald de Wit, ${ }^{15}$ Inge M. van Oort, ${ }^{16}$ Winald R. Gerritsen, ${ }^{8}$ Carin A. Uyl-de Groot ${ }^{1}$

\section{Abstract}

In castration-resistant prostate cancer (CRPC), several life-prolonging drugs have been registered, but patientreported outcomes in daily practice are scare. In our study, 151 patients with CRPC completed quality of life $(Q \circ L)$ questionnaires. Although the majority received life-prolonging drugs, QoL deteriorated during the course of CRPC. Supportive care should be timely thought of to maintain QoL as long as possible.

Background: The purpose of this study was to determine generic, cancer-specific, and prostate cancer-specific health-related quality of life (HRQoL), pain and changes over time in patients with metastatic castration-resistant prostate cancer (mCRPC) in daily practice. Patients and Methods: PRO-CAPRI is an observational, prospective study in 10 hospitals in the Netherlands. Patients with mCRPC completed the EQ-5D, European Organization for the Research and Treatment of Cancer Quality of Life Questionnaire (EORTC QLQ-C30), and Brief Pain Inventory-Short Form (BPI-SF) every 3 months and European Organization for the Research and Treatment of Cancer Quality of Life Questionnaire-Prostate Cancer Module (EORTC QLQ-PR25) every 6 months for a maximum of 2 years. Subgroups were identified based on chemotherapy pretreatment. Outcomes were generic, cancer-specific, and prostate cancer-specific HRQoL and self-reported pain. Descriptive statistics were performed including changes over time and minimal important differences (MID) between subgroups. Results: In total, 151 included patients answered 873 questionnaires. The median follow-up from the start of the study was 19.5 months, and $84 \%$ were treated with at least 1 life-prolonging agent. Overall, patients were in good clinical condition (Eatern Cooperative Oncology Group performance status $0-1$ in $78 \%$ ) with normal baseline hemoglobin, lactate dehydrogenase, and alkaline phosphatase. At

\section{M.C.P.K. and H.M.W. contributed equally to this article.}

${ }^{1}$ Institute for Medical Technology Assessment, Erasmus School of Health Policy and

Management, Erasmus University Rotterdam, Rotterdam, the Netherlands

${ }^{2}$ Department of Internal Medicine, Amphia Hospital, Breda, the Netherlands

${ }^{3}$ Department of Medical Oncology, Cancer Center Amsterdam, Amsterdam UMC,

Vrije Universiteit, Amsterdam, the Netherlands

${ }^{4}$ Department of Oncology, Isala, Zwolle, the Netherlands

${ }^{5}$ Department of Urology, Amsterdam UMC, Vrije Universiteit, Amsterdam, the

Netherlands

${ }^{6}$ Department of Internal Medicine, TerGooi Ziekenhuizen, Hilversum, the

Netherlands

${ }^{7}$ Department of Internal Medicine, OLVG, Amsterdam, the Netherlands

${ }^{8}$ Department of Medical Oncology, Radboud University Medical Center, Nijmegen, the Netherlands

${ }^{9}$ Department of Internal Medicine, Northwest Clinics, Alkmaar, the Netherlands

${ }^{10}$ Department of Urology, Medical Center Leeuwarden, Leeuwarden, the Netherlands

${ }^{11}$ Department of Internal Medicine, Reinier de Graaf Gasthuis and Reineir Haga Prostate Cancer Center, Delft, the Netherlands
${ }^{12}$ Department of Internal Medicine, Zuyderland Medical Center, Heerlen-SittardGeleen, the Netherlands

${ }^{13}$ Department of Urology, Northwest Clinics, Alkmaar, the Netherlands

${ }^{14}$ Department of Internal Medicine, Jeroen Bosch Hospital, 's-Hertogenbosch, the Netherlands

${ }^{15}$ Department of Medical Oncology, Erasmus MC Daniel den Hoed Cancer Center, Rotterdam, the Netherlands

${ }^{16}$ Department of Urology, Radboud University Medical Center, Nijmegen, the Netherlands

Submitted: Sep 12, 2019; Revised: Nov 18, 2019; Accepted: Nov 27, 2019

Address for correspondence: Malou C.P. Kuppen, MD, Institute for Medical Technology Assessment, Erasmus School of Health Policy and Management, Erasmus University Rotterdam, P.O. Box 1738, 3000 DR Rotterdam, the Netherlands E-mail contact: kuppen@ehspm.eur.nl 


\section{Real-world Quality of Life in Castration-resistant Prostate Cancer}

inclusion, generic HRQoL was high with a mean EQ visual analog score of 73.2 out of 100 . The lowest scores were reported on role and physical functioning (mean scores of 69 and 76 of 100, respectively), and fatigue, pain, and insomnia were the most impaired domains. These domains deteriorated in $>50 \%$ of patients. Conclusion: Although most patients were treated with new treatments during follow-up, mCRPC has a negative impact on HRQoL with deterioration in all domains over time, especially role and physical functioning. These domains need specific attention during follow-up to maintain HRQoL as long as possible by timely start of adequate supportive care management.

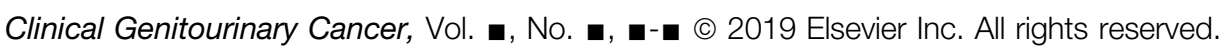

Keywords: Life-prolonging drugs, Metastatic castration-resistant prostate cancer, Patient-reported outcomes, Real-world outcomes, Registry

\section{Introduction}

The survival of patients with metastatic castration resistant prostate cancer (mCRPC), that is progression of disease on androgen deprivation therapy, is not likely to extend beyond 14 months with only best supportive care. ${ }^{1}$ Several life-prolonging drugs (LPDs), such as chemotherapy (ie, docetaxel, cabazitaxel), androgen-receptor targeting treatments (ie, abiraterone, enzalutamide), and radionuclide therapy (ie, radium-223), have shown a survival benefit compared with placebo. ${ }^{2-8}$ In a contemporary cohort with access to these new LPDs, we observed a median overall survival of 26 months. ${ }^{9}$

mCRPC has a negative impact on health-related quality of life (HRQoL) with a decline in HRQoL over time. ${ }^{1,10-17}$ Deterioration occurs in general domains as well as specific symptoms such as pain, fatigue, and appetite loss. ${ }^{12}$ However, these results are derived from trials performed in the era before the registration of new LPDs. ${ }^{1,12,15,16}$ In the pivotal phase III trials, the LPDs showed a delay in HRQoL deterioration and pain progression in both chemotherapy-naive (CTx-naive) and postchemotherapy (post-CTx) disease phases, ${ }^{18-21}$ but adverse events of new agents can also add to the symptom burden in mCRPC.

There remains a paucity of data concerning treatment sequencing and direct comparisons of LPDs in randomized trials. Moreover, cumulating evidence on real-world data points toward the fact that trials utilize highly selected populations with significantly better outcomes that are commonly not generalizable to an oncology practice. ${ }^{9}$ Benefits of LPDs in trials are comparable and economic costs are in the same range, making patient-reported outcomes (PROs) of special interest in order to determine the best treatment. The use of PROs in daily practice can also inform physicians on efficacy and tolerability, increase patient satisfaction, and improve symptom control and supportive care measures. ${ }^{22}$

The high proportion of patients experiencing HRQoL deterioration owing to either disease- or treatment-related symptoms, the lack of discriminative results from trials, and the gap between these trials and real-world practice underline the necessity for PROs in daily practice. The objective of this study is therefore to determine generic, cancer-specific, and prostate cancer-specific HRQoL and changes over time in patients with $\mathrm{mCRPC}$ using data from a patient registry in the Netherlands.

\section{Patients and Methods Study Design and Setting}

PRO-CAPRI is a prospective observational cohort study in 10 hospitals in the Netherlands. The study aimed to evaluate HRQoL, pain, and resource use outside the hospital in daily practice using validated questionnaires. The study was approved by a central and local medical ethics committee and hospital board before the start of inclusion. The PRO-CAPRI study is registered in the Dutch Trial Registry as NL3934 (NTR4096). PRO-CAPRI is a side study of the CAstration-resistant Prostate cancer RegIstry (CAPRI) registered as NL3440 (NTR3591). The methods of the CAPRI registry have been described in depth previously.

\section{Objectives}

The objectives are to determine generic, cancer-specific, and prostate cancer-specific HRQoL, pain, and changes over time in patients with $\mathrm{mCRPC}$ in daily practice.

\section{Participants}

Patients diagnosed with mCRPC between January 1, 2010 and December 31, 2015 were eligible for inclusion, conforming to the CAPRI inclusion criteria.' Patients were eligible for the PROCAPRI study from diagnosis of CRPC to 4 weeks after the start of the first post-docetaxel treatment. Eligible patients provided written informed consent to the treating physician at the hospital site. All PRO-CAPRI patients were also included in the CAPRI registry.

Subgroups were created based on the disease state at inclusion, namely chemotherapy-naive state (CTx-naive [ie, no prior docetaxel treatment]) and (post-) chemotherapy state (post-CTx [ie, current docetaxel or post-docetaxel treatment]).

\section{Study Size}

In PRO-CAPRI, 167 participants were included out of the total of 3616 patients with mCRPC that were included in the CAPRI registry.

\section{Follow-up and Data Collection}

PRO-CAPRI started in June 2013 with 4 participating hospitals, but because of slow accrual, the protocol was amended after 1 year to include an additional 6 hospitals and prolong the inclusion period for 6 months. This amendment also included the addition of the pain-specific questionnaire, the Brief Pain Inventory-Short Form (BPI-SF).

The baseline evaluation of consenting patients consisted of 4 questionnaires (EQ-5D, European Organization for the Research and Treatment of Cancer Quality of Life Questionnaire [EORTC 
QLQ-C30], European Organization for the Research and Treatment of Cancer Quality of Life Questionnaire-Prostate Cancer Module [EORTC QLQ-PR25], and after the amendment, BPI-SF) and commonly used demographic items, namely age, socioeconomic status, marital status, and educational level. After baseline measurement, EQ-5D, EORTC QLQ-C30, and BPI-SF were repeated every 3 months, and EORTC QLQ-PR25 every 6 months. All patients were followed until death, withdrawal of consent, or end of study duration (either a total follow-up period of 2 years from the start of the study or December 31, 2017).

A case record form linked the participating patient to the CAPRI database, combining HRQoL with the clinical characteristics.

\section{Outcome}

The primary outcome was generic HRQoL, measured with EQ5D. The first part of the EQ-5D is a generic 5-dimensional questionnaire on a 5-point Likert scale, which was transformed into utility or EQ-5D index value based on Dutch population norms. ${ }^{23}$ The second part is a visual analogue scale (VAS). ${ }^{24}$

The secondary outcomes were cancer-specific HRQoL, prostate cancer-specific HRQoL, and pain. The EORTC QLQ-C30 (cancer-specific HRQoL) and EORTC QLQ-PR25 (prostate cancerspecific HRQoL) include 55 questions in different HRQoL domains, including functional scales, symptom scales, and a global health status. For the majority of items, a 4-point Likert-type response scale was used. Exception is the global health status, where a 7-point scale was used. All EORTC QLQ-C30 and EORTC QLQ-PR25 scales were linearly transformed to a scale from 0 to 100 according to the scoring manual. ${ }^{25,26}$ The BPI-SF assesses severity of pain (4 items), impact of pain on daily function (7 items), location of pain, pain medication, and amount of pain relief in the past 24 hours or the past week. The areas were measured on a scale from 0 to 10 , with 0 indicating "no pain" and 10 indicating "worst possible pain." ${ }^{27}$ Clinically relevant pain was defined as a score of $\geq 4$ on pain severity. Supplemental Table 1 (in the online version) shows an overview of the used questionnaires.

Both the primary and secondary outcomes are measured at baseline (ie, inclusion) and over time. A minimally important difference (MID) was used to assess clinically relevant changes. ${ }^{27-30}$ The thresholds for MIDs are also shown in Supplemental Table 1 (in the online version). Time to first MID deterioration was calculated in months from the date of first questionnaire to the date of first MID deterioration.

\section{Missing Values}

Missing values were handled based on the scoring manual for the specific questionnaires. In EQ-5D, the index value and VAS were calculated if all domains were present. ${ }^{24}$ For EORTC QLQ-C30, EORTC QLQ-PR25, and BPI-SF, averages were calculated if more than one-half of the questions were completed per scale. ${ }^{25-27}$

\section{Statistical Analysis}

The compliance rate was calculated as the number of patients returning a questionnaire divided by the total number of evaluable patients per questionnaire. Baseline characteristics were measured in the period of 3 months prior to 3 months after inclusion. Descriptive statistics were used to describe the study population with subgroups per disease state at inclusion. Data on HRQoL were presented as mean changes from baseline and proportion with MID. The McNemar test was used for differences in proportion with MID between 6 and 12 months for subgroups. The independent sample $t$ test, Mann-Whitney $U$ test, or $\chi^{2}$ test were used to compare parametric continuous, nonparametric continuous, and categorical variables, respectively, between CTx-naive and post-CTx patients. A $P$-value of .05 or less was considered statistically significant. IBM SPSS Statistics Version 24.0 (IBM, Armonk, NY) was used for all analyses.

\section{Results}

In total, 167 patients were included in the PRO-CAPRI study. Nine patients were excluded for failing to meet the inclusion criteria $(n=7)$ or missing informed consent $(n=2)$. Seven of the 158 patients who were sent the first questionnaire did not respond, either owing to death $(n=4)$, withdrawal of consent $(n=2)$, or inability to answer $(n=1)$. Baseline questionnaires were evaluable for 151 patients (Figure 1).

In total, 873 questionnaires were completed, and the median number of questionnaires per patient was 6 (range, 1-9). The median follow-up from the first questionnaire was 19.5 months (IQR, 13-25 months). Thirty-eight (25\%) patients completed all 9 questionnaires. Termination of the study before the maximum follow-up of 2 years occurred in $113(75 \%)$ patients, owing to death $(\mathrm{n}=56$; $37 \%$ ), lost-to-follow-up ( $\mathrm{n}=22 ; 15 \%)$, withdrawal of informed consent $(n=9 ; 6 \%)$, or database cutoff $(n=26 ; 17 \%)$. The compliance rate ranged from $94 \%$ to $100 \%$ per questionnaire, except for BPI-SF, which was added during the study after a protocol amendment (see Supplemental Table 2 in the online version).

\section{Treatment Characteristics}

At inclusion, $112(74 \%)$ patients were in the CTx-naive state, and $39(26 \%)$ patients were in the post-CTx state. At the time of the first questionnaire, $37(33 \%)$ patients in the CTx-naive state were treated with LPD, mainly enzalutamide ( $\mathrm{n}=27 ; 24 \%)$, whereas in the post-CTx state, most patients were treated with docetaxel $(\mathrm{n}=17$; 44\%). During follow-up, $84 \%$ of patients were treated with at least $1 \mathrm{LPD}$, mainly enzalutamide $(\mathrm{n}=89 ; 59 \%)$ or docetaxel ( $n=65 ; 43 \%)$ (Table 1$)$.

\section{Patient and Disease Characteristics}

At mCRPC diagnosis, patients included in the PRO-CAPRI study were younger $(72$ vs. 75 years; $P<.01$ ) and had higher hemoglobin $(8.3$ vs. $8.0 \mathrm{mmol} / \mathrm{L} ; P=.01)$ compared with the total mCRPC population in the CAPRI registry (see Supplemental Table 3 in the online version).

CTx-naive patients were older (median 75 vs. 71 years; $P=.02$ ), had less prevalent bone metastases (73\% vs. $82 \% ; P=.03)$, and had lower educational level $(P=.03)$ at inclusion than post-CTx patients (Table 1). PSA tended to be lower in CTx-naive patients (median, 36 vs. $86 \mu \mathrm{g} / \mathrm{L} ; P=.06$ ).

\section{Generic HRQoL (EQ-5D)}

Generic HRQoL was high, with a mean EQ VAS of 73.2 of 100 and EQ-5D index value of 0.82 of 1 at inclusion. Most problems were reported on pain/discomfort (55\%) and mobility (48\%). No 


\section{Real-world Quality of Life in Castration-resistant Prostate Cancer}

\section{Figure 1 Flowchart of Patient Inclusion}

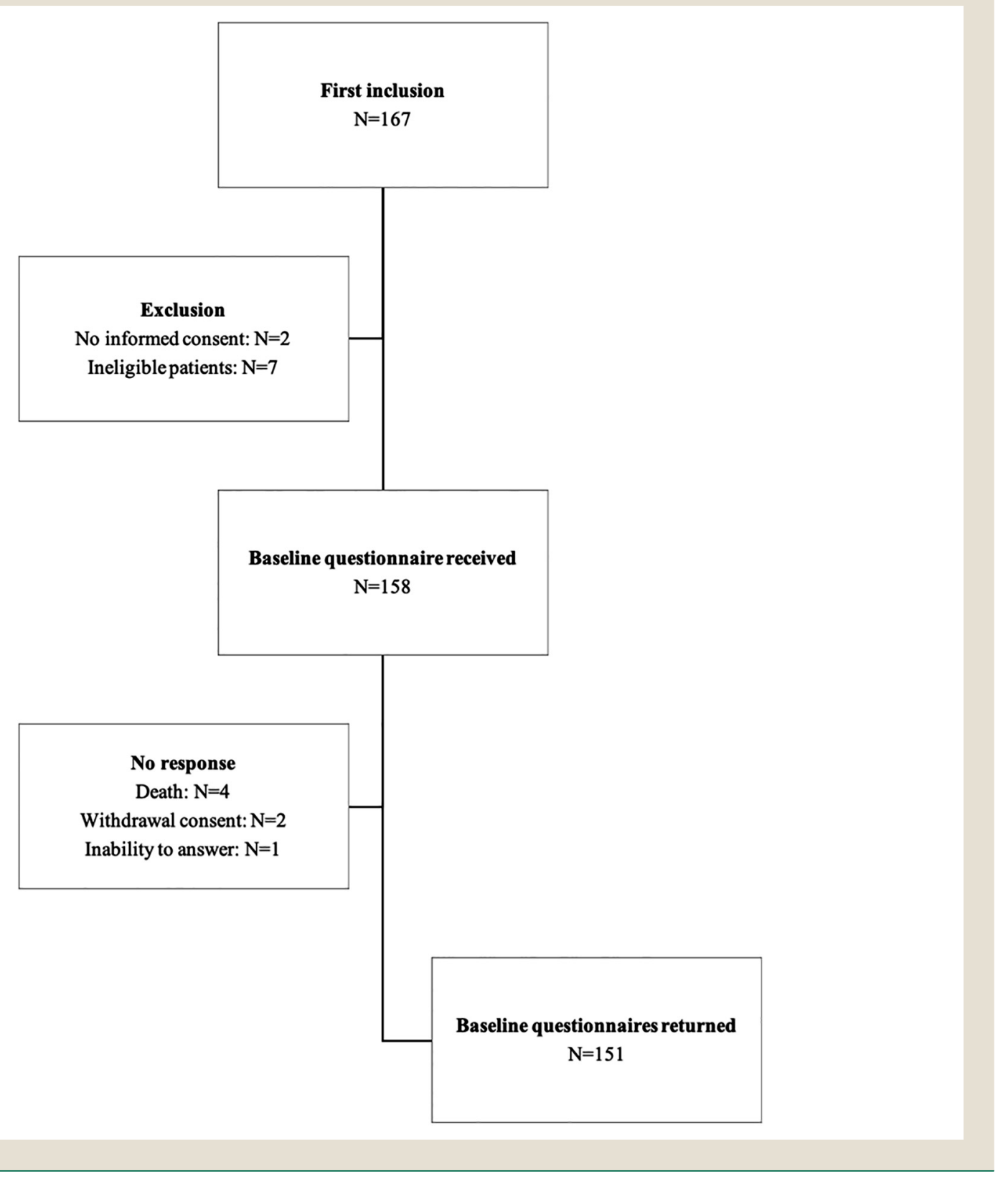

differences between disease state were observed in generic HRQoL (Figure 2A, Supplemental Table 4 [in the online version]).

EQ VAS deteriorated over time, but changes were small, and the mean change did not reach MID during 24 months of follow-up (Figure 3A). There were no differences in proportion with MID deterioration at 6 and 12 months (Table 2, Supplemental Table 5 [in the online version]). The median time to MID deterioration on generic HRQoL was 10.8 months for EQ VAS, without differences between CTx-naive and post-CTx patients (Table 3, Supplemental Table 6 [in the online version]).

\section{Cancer-specific HRQoL (EORTC QLQ-C30)}

Figure $2 \mathrm{~A}$ and $\mathrm{B}$ show cancer-specific HRQoL at inclusion. Role (ie, patient's ability to perform daily activities, leisure time activities, and/or work) and physical functioning were most affected in cancerspecific HRQoL (mean scores of 69 and 76 of 100, respectively). CTX-naive patients had significant but not relevant lower levels of emotional functioning compared with post-CTx patients (mean scores of 81 vs. $88 ; P=.02$ ). Most symptoms were measured on scales of fatigue, pain, and insomnia, without differences in subgroups per disease state (Figure 2A and B).

Deterioration was seen on all functioning domains of EORTC QLQ-C30, except for emotional functioning (Figures 3B-G). The proportion of CTx-naive patients with MID after 12 months was higher compared with after 6 months in global health status (32\% vs. $18 \% ; P=.03$ ), physical functioning ( $44 \%$ vs. $27 \% ; P=.02$ ), role functioning ( $45 \%$ vs. $27 \% ; P=.02$ ), and social functioning $(35 \%$ vs. $19 \% ; P=.01)$. In post-CTx patients, no differences in proportion 
Malou C.P. Kuppen et al

Table 1 Patient and Disease Characteristics per Disease State

\begin{tabular}{|c|c|c|c|c|}
\hline & Total $N=151$ & CTx-naive $N=112$ & Post-CTx N $=39$ & $P$ Value \\
\hline Age, y & & & & .020 \\
\hline Median (IQR) & $74(68-80)$ & $75(68-81)$ & $71(68-75)$ & \\
\hline Range & $54-95$ & $54-95$ & $58-84$ & \\
\hline ECOG performance status, \% & & & & .235 \\
\hline 0 & 38 & 39 & 36 & \\
\hline 1 & 40 & 35 & 54 & \\
\hline$>1$ & 9 & 10 & 5 & \\
\hline Unknown & 13 & 16 & 5 & \\
\hline Gleason score, \% & & & & .431 \\
\hline$\leq 7$ & 34 & 35 & 31 & \\
\hline $8-10$ & 56 & 53 & 64 & \\
\hline No histology & 3 & 5 & 0 & \\
\hline Metastasis biopsy & 1 & 1 & 3 & \\
\hline Unknown & 6 & 7 & 3 & \\
\hline Charlson comorbidity index, \% & & & & .565 \\
\hline 6 & 69 & 66 & 77 & \\
\hline $7-8$ & 25 & 27 & 21 & \\
\hline $9-10$ & 5 & 6 & 3 & \\
\hline$>10$ & 1 & 1 & 0 & \\
\hline Unknown & 0 & 0 & 0 & \\
\hline \multicolumn{5}{|l|}{ Disease state, $\%$} \\
\hline $\mathrm{N} 1 / \mathrm{N} 0 / \mathrm{Nx}$ & $49 / 13 / 38$ & $44 / 13 / 44$ & $64 / 15 / 21$ & .749 \\
\hline M1/M0/Mx (bone) & $76 / 8 / 17$ & $73 / 5 / 22$ & $82 / 18 / 0$ & .031 \\
\hline M1/M0/Mx (visceral) & $9 / 31 / 60$ & $5 / 25 / 70$ & $18 / 49 / 33$ & .387 \\
\hline $\begin{array}{l}\text { Period from castration to } \\
\text { mCRPC, mos }\end{array}$ & & & & .105 \\
\hline Median (IQR) & $15.1(9-28)$ & $16.5(9-32)$ & $13.0(7-22)$ & \\
\hline Unknown, \% & 0 & 0 & 0 & \\
\hline $\begin{array}{l}\text { Period from mCRPC to inclusion } \\
\text { PRO-CAPRI, mos }\end{array}$ & & & & $<.001$ \\
\hline Median (IQR) & $7.0(2.0-21.0)$ & $4.7(1-14)$ & $19.4(10-29)$ & \\
\hline Unknown, \% & 0 & 0 & 0 & \\
\hline Hemoglobin, mmol/L & & & & .479 \\
\hline Median (IQR) & $8.0(7.3-8.5)$ & $8.1(7.5-8.5)$ & $8.0(7.1-8.4)$ & \\
\hline Unknown, \% & 2.6 & 3 & 3 & \\
\hline Lactate dehydrogenase, U/L & & & & .341 \\
\hline Median (IQR) & $213(185-261)$ & $211(182-259)$ & $218(187-281)$ & \\
\hline Unknown, \% & 7 & 7 & 5 & \\
\hline Alkaline phosphatase, U/L & & & & .421 \\
\hline Median (IQR) & $103(72-173)$ & $102(72-168)$ & $113(76-254)$ & \\
\hline Unknown, \% & 2 & 3 & 0 & \\
\hline Prostate-specific antigen, $\mu \mathrm{g} / \mathrm{L}$ & & & & .061 \\
\hline Median (IQR) & $40.4(12-121)$ & $36.0(11-106)$ & $86.0(14-180)$ & \\
\hline Unknown, \% & 2 & 3 & 0 & \\
\hline Marital state, \% & & & & .210 \\
\hline Married/living together & 85 & 83 & 90 & \\
\hline Single/not living together & 5 & 4 & 8 & \\
\hline Divorced & 3 & 4 & 0 & \\
\hline Widowed & 8 & 10 & 3 & \\
\hline
\end{tabular}




\section{Real-world Quality of Life in Castration-resistant Prostate Cancer}

\section{Table 1 Continued}

\begin{tabular}{|c|c|c|c|c|}
\hline & Total $N=151$ & CTx-naive $N=112$ & Post-CTx N $=39$ & $P$ Value \\
\hline Educational level, \% ${ }^{\mathrm{a}}$ & & & & .030 \\
\hline None & 1 & 1 & 0 & \\
\hline Low & 39 & 45 & 23 & \\
\hline Middle & 15 & 11 & 26 & \\
\hline High & 38 & 35 & 46 & \\
\hline Other/unknown & 8 & 9 & 5 & \\
\hline Current profession, \% & & & & .395 \\
\hline Employed & 8 & 7 & 10 & \\
\hline Entrepreneur & 7 & 10 & 0 & \\
\hline Incapacitated & 3 & 2 & 5 & \\
\hline Retired/early retired & 79 & 78 & 82 & \\
\hline Other/unknown & 3 & 4 & 3 & \\
\hline \multicolumn{5}{|c|}{ Treatment at inclusion, $\%{ }^{\mathrm{b}}$} \\
\hline None & 24 & 32 & 0 & $<.001$ \\
\hline No LPD & 26 & 35 & 0 & $<.001$ \\
\hline LPD & 50 & 33 & 100 & $<.001$ \\
\hline Docetaxel & 11 & 0 & 44 & $<.001$ \\
\hline Cabazitaxel & 1 & 0 & 3 & .089 \\
\hline Abiraterone acetate & 12 & 9 & 18 & .125 \\
\hline Enzalutamide & 27 & 24 & 36 & .001 \\
\hline Radium-223 & 0 & 0 & 0 & - \\
\hline Study drug & 0 & 0 & 0 & - \\
\hline \multicolumn{5}{|c|}{ Treatment during follow-up, \% ${ }^{\mathrm{c}}$} \\
\hline None & 6 & 9 & 0 & .053 \\
\hline No LPD & 15 & 18 & 8 & .128 \\
\hline LPD & 84 & 80 & 97 & .008 \\
\hline Docetaxel & 43 & 44 & 41 & .767 \\
\hline Cabazitaxel & 19 & 14 & 31 & .023 \\
\hline Abiraterone acetate & 25 & 23 & 28 & .533 \\
\hline Enzalutamide & 59 & 59 & 59 & .996 \\
\hline Radium-223 & 11 & 11 & 10 & .936 \\
\hline Study drug & 3 & 4 & 3 & .762 \\
\hline
\end{tabular}

All baselines measured are measured within 3 months prior or after the start of study. Percentages may exceed $100 \%$ owing to rounding.

$P$ values calculated for differences in time to first minimally important difference between CTx-naive and post-CTx patients.

Abbreviations: $\mathrm{ADT}=$ androgen deprivation therapy; $\mathrm{CTX}$-naive = no or no prior docetaxel chemotherapy at inclusion; ECOG = Eastern Cooperative Oncology Group; IQR = interquartile range; $\mathrm{LPD}=$ life prolonging drug (either docetaxel, cabazitaxel, abiraterone, enzalutamide or radium-223); mCRPC $=$ metastastic castration-resistant prostate cancer; post-CTx $=$ current or post-docetaxel chemotherapy at inclusion.

${ }^{a}$ Educational level converted to classes according to the Dutch Central Bureau of Statistics (CBS). ${ }^{31}$

${ }^{\mathrm{b}}$ Any systemic treatment at time of first questionnaire.

${ }^{c}$ Any systemic treatment at time of second or later questionnaires.

with MID deterioration after 6 and 12 months was seen. Symptoms increased over time, with the highest proportion of patients with MID in fatigue and appetite loss. The proportion of patients with MID after 12 months was higher than after 6 months for pain $(22 \%$ vs. $36 \% ; P<$ .01 ), which was only present in the CTx-naive subgroup (see Supplemental Table 5 in the online version).

All functioning domains of EORTC QLQ-C30 deteriorated approximately 1 year after inclusion, except for emotional functioning (median, 26.6 months) (Table 3). The median time to deterioration of the symptoms fatigue and pain were, respectively, 8.2 and 15.3 months.

\section{Prostate Cancer-specific HRQoL (EORTC QLQ-PR25)}

At inclusion, 31 (21\%) patients reported any sexual activity measured with EORTC QLQ-PR25, with higher activity levels in CTx-naive patients than in post-CTx patients (mean, 8.5 vs. 1.4; $P=.02$ ). Prostate cancer-specific symptoms were mostly present as urinary symptoms at inclusion. CTx-naive patients reported more bowel symptoms than post-CTx patients (mean 8.9 vs. $3.7 ; P=$ $.04)$. During follow-up, sexual activity and prostate cancer-specific symptoms remained stable, and no clinically relevant deterioration was observed. 
Figure 2 Health-related Quality of Life Measured at Study Inclusion. A, Mean Scores of Functioning Scales. High Scores Indicate High Level of Functioning. B, Mean Scores of Symptom Scales. High Scores Indicate High Symptom Burden. C, Mean Scores of Pain. High Scores Indicate High Pain Severity or Interference. Error Bars Represent 95\% Confidence Intervals. *Significant Differences at Level $P<.05$

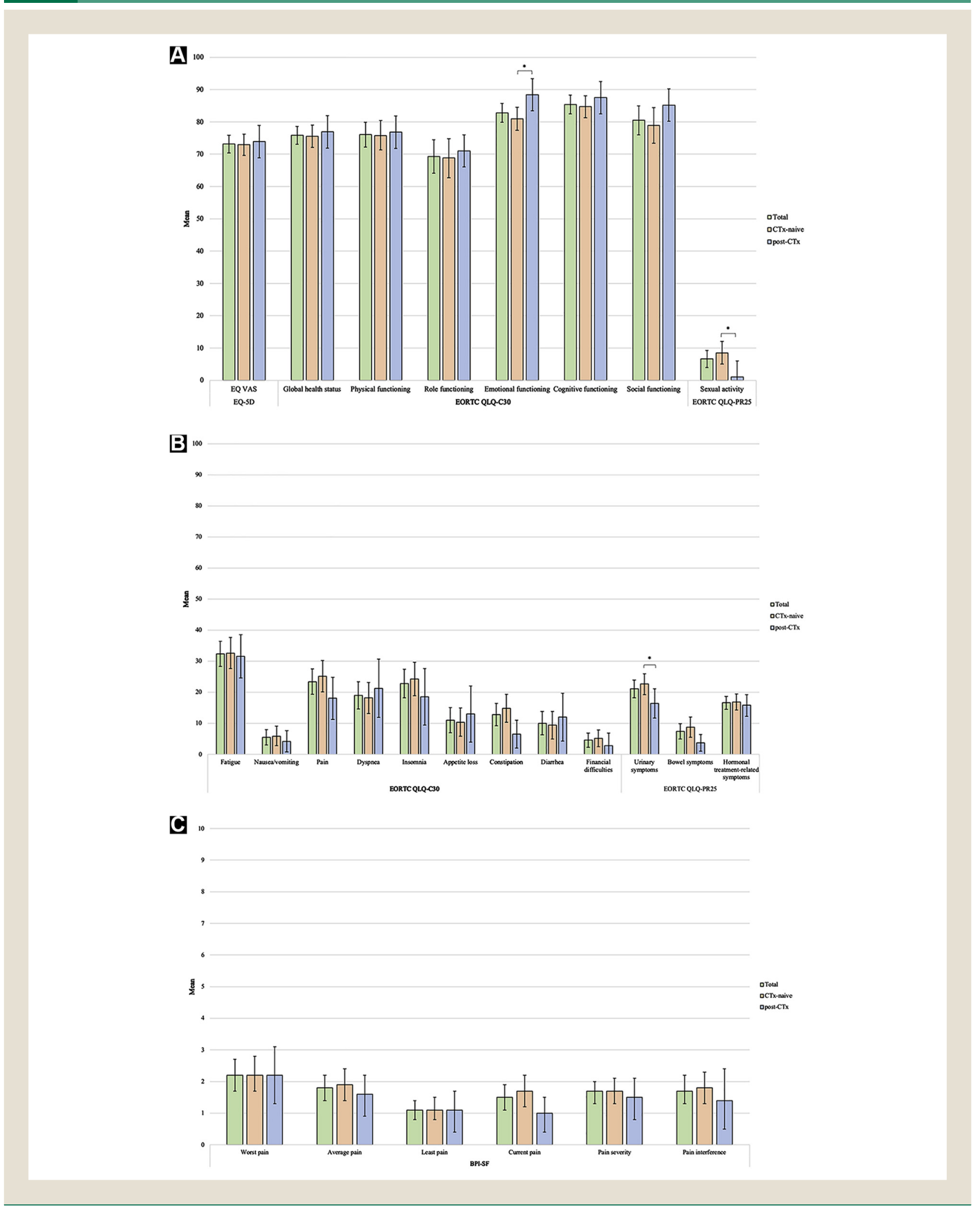

Abbreviations: BPI-SF = Brief Pain Inventory-Short Form; CTX-naive $=$ no or no prior docetaxel chemotherapy at inclusion; post-CTX $=$ current or post-docetaxel chemotherapy at inclusion; EORTC QLQ-C30 = European Organization for the Research and Treatment of Cancer Quality of Life Questionnaire; EORTC QLQ-PR25 = European Organization for the Research and Treatment of Cancer Quality of Life Questionnaire-Prostate Cancer Module; VAS = visual analog scale. 


\section{Real-world Quality of Life in Castration-resistant Prostate Cancer}

\section{Pain (BPI-SF)}

The mean pain severity and interference were low at inclusion, without differences between subgroups (Figure 2C). Sixteen percent (17 of 108 patients with baseline BPI-SF) reported clinically relevant pain at inclusion.

Thirty-six percent of patients without clinical meaningful pain at inclusion had MID deterioration during follow-up. Eight (47.1\%) of 17 patients with clinical meaningful pain at inclusion had evaluable follow-up questionnaires, with $4(23.5 \%)$ reporting MID improvement of pain. In CTx-naive patients, the proportion of patients with MID after 12 months was higher for "worst" (29\% vs. $18 \% ; P=.04)$ and "average" $(24 \%$ vs. $13 \% ; P=.02)$ pain and pain interference on daily functioning $(26 \%$ vs. $11 \% ; P<.01)$ than after 6 months (see Supplemental Table $5 \mathrm{a}$ in the online version).

No differences between CTx-naive and post-CTx patients were found in time to deterioration except for "worst" pain (see Supplemental Table 6 in the online version). CTx-naive patients had a significantly longer time to deterioration on "worst" pain than post-CTx patients (24.5 vs. 9.9 months, respectively; $P=.04$ ).

\section{Discussion}

To our knowledge, this is the largest contemporary real-world longitudinal analysis of HRQoL during mCRPC. Previous research mainly focused on patients treated in randomized controlled trials, but results from these trials cannot be easily generalized to the real-world practice. ${ }^{9}$ The absence of complicated inclusion and exclusion criteria in our study warrants the reflection of a real-world population in current daily practice.

In this study, we showed that at inclusion, baseline HRQoL was relatively high. Most of our patients were in an early disease phase, with $75 \%$ of patients without docetaxel pretreatment and a short interval from diagnosis of castrate-resistance to inclusion into the study. Previously published mCRPC cohorts reported lower HRQoL. ${ }^{12,32}$ For example, the mean EQ-5D index value was 0.82 in our study, compared with 0.64 to 0.74 in other reports. ${ }^{12,32}$ However, differences between our study and previous reports can be explained by differences in patient selection, the availability of life-prolonging therapeutic options, and international valuation of HRQoL measurement. ${ }^{33,34}$ This contemporary cohort indicates that in Dutch daily practice, generic HRQoL is high in the early mCRPC state. ${ }^{12,14,15,32}$ Most baseline symptoms were identified in role (ie, patient's ability to perform daily activities, leisure time activities, and/or work) and physical functioning, with high symptom burden on pain, fatigue, and insomnia.

Deterioration was seen in almost all domains of HRQoL. Deterioration in HRQoL is part of the normal aging process, and scores on cognitive, emotional, and social functioning are comparable to the European population norms of the same age group $(\geq$ 70 years). ${ }^{35}$ However, we found low scores on role and physical functioning at inclusion, probably showing the impact of mCRPC on these domains. ${ }^{35}$ Role and physical functioning were also prone to deterioration. Therefore, specific attention for these domains at the start of new systemic treatment and during follow-up of patients with mCRPC is needed to maintain HRQoL as long as possible.
A delay in HRQoL and pain progression has been reported in randomized controlled trials of new LPDs. ${ }^{18-21}$ Eighty-four percent of patients in our study were also treated with LPDs during followup. Owing to small sample sizes, we were not able to calculate differences between treated and untreated patients, and more specifically between treatments. In our total mCRPC population, the median time to pain deterioration ("worst" pain) was 24.5 months in CTX-naive and 9.9 months in post-CTX patients. This time to progression on "worst" pain is in agreement with the chemotherapynaive COU-AA-302 treatment arm (25.8 months $)^{36}$ and in the post-chemotherapy COU-AA-301 treatment arm (7.4 months). ${ }^{37}$ Comparison with clinical trials, however, warrants caution owing to differences in patient selection, outcome measures, and the definition of MID compared with our real-world population.

In prostate cancer-specific HRQoL, we found low sexual activity and mostly urinary symptoms at baseline. A population-based survey in the United Kingdom showed that sexual activity was low among all stages of prostate cancer. ${ }^{38}$ Although younger patients were concerned about the lack of sexual activity, less than one-half of the patients were offered treatment to improve sexual health. ${ }^{38}$ The baseline assessment in individual patients with mCRPC can address problems and concerns about sexual health and guide individual treatment. However, similar to other research, no trends in prostate-cancer specific HRQoL were observed during follow-up. ${ }^{14}$ Therefore, the EORTC QLQ-PR25 seems of low additional value when it comes to monitoring treatment effects and tolerability.

An important limitation of this study was the relatively small sample size. Only 4 percent of all patients included in the CAPRIregistry were included in the PRO-CAPRI study. At baseline mCRPC diagnosis, patients in the PRO-CAPRI study tended to be in better clinical condition than patients in the CAPRI-registry. Therefore, results are possibly not generalizable for the total Dutch population. The second limitation of this study was the nonrandomized study design that made it impossible to compare the individual new treatments. Subgroups per treatment were too small for reliable analyses of changes in HRQoL.

\section{Conclusion}

To conclude, in spite of the availability of LPDs, deterioration was seen in almost all domains of HRQoL with the domains role and physical functioning especially prone to deterioration. Therefore, specific attention during follow-up is needed in order to maintain HRQoL as long as possible by timely starting supportive care management. Incorporating individual PRO assessment in daily clinical practice can possibly aid physicians in treatment decisions, monitoring treatment effects and tolerability, and improving symptom control.

\section{Clinical Practice Points}

- Patients with mCRPC experience a decline in HRQoL over time. Several drugs, registered for mCRPC based on a survival benefit, also show a delay in HRQoL deterioration and pain progression. However, there is a paucity of data on HRQoL in a real-world population with $\mathrm{mCRPC}$ treated with these new drugs. 
Changes in HRQoL Over Time per Disease State. A, Mean Changes of EQ-VAS (Generic HRQoL). B, Mean Changes of Global Health Status (Cancer-specific HRQoL). C, Mean Changes of Physical Functioning (Cancer-specific HRQoL). D, Mean Changes of Role Functioning (Cancer-specific HRQOL). E, Mean Changes of Emotional Functioning (Cancer-specific HRQoL). F, Mean Changes of Cognitive Functioning (Cancer-specific HRQoL). G, Mean Changes of Social Functioning (Cancer-specific HRQ0L). Mean Changes From Inclusion. Error Bars Represent 95\% Confidence Interval and Red Line Represents MID

$\mathbf{A}$

Total

CTx-naive

post-CTx

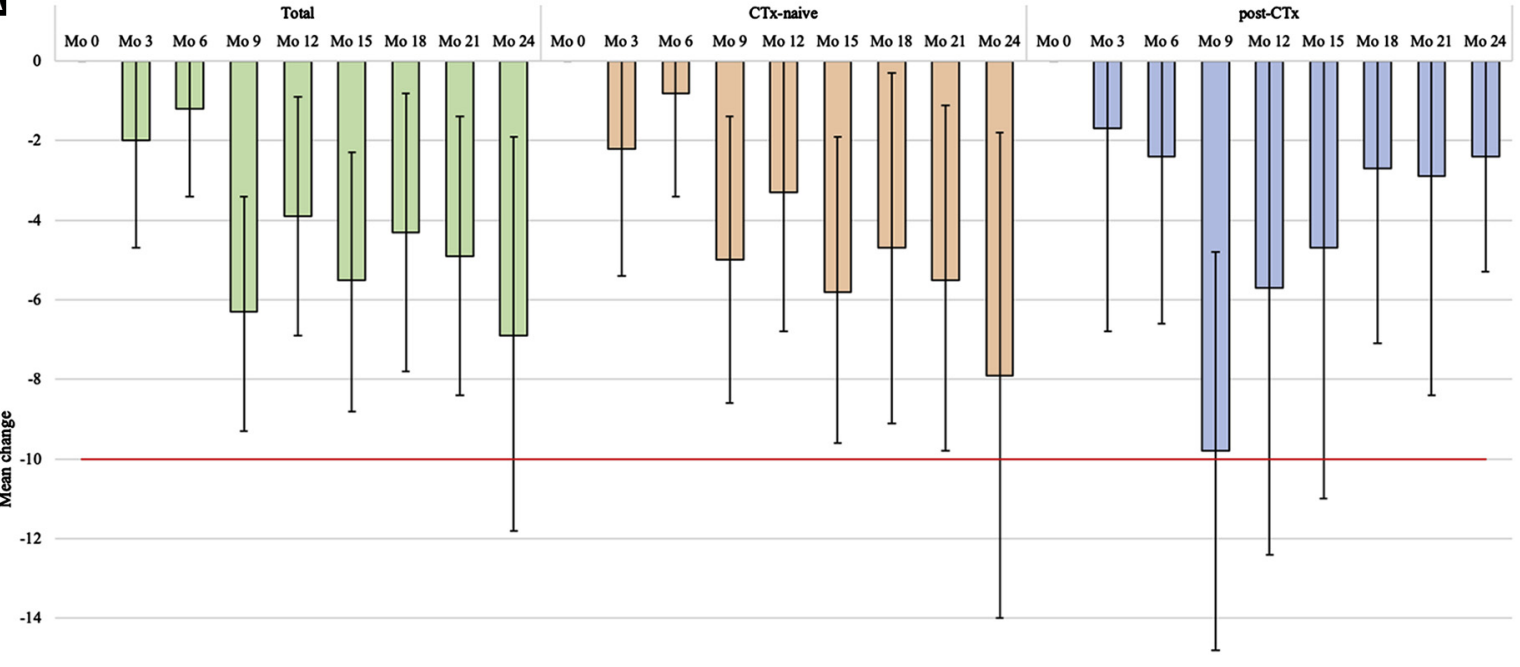

$-16$

$-18$

$-20$

B

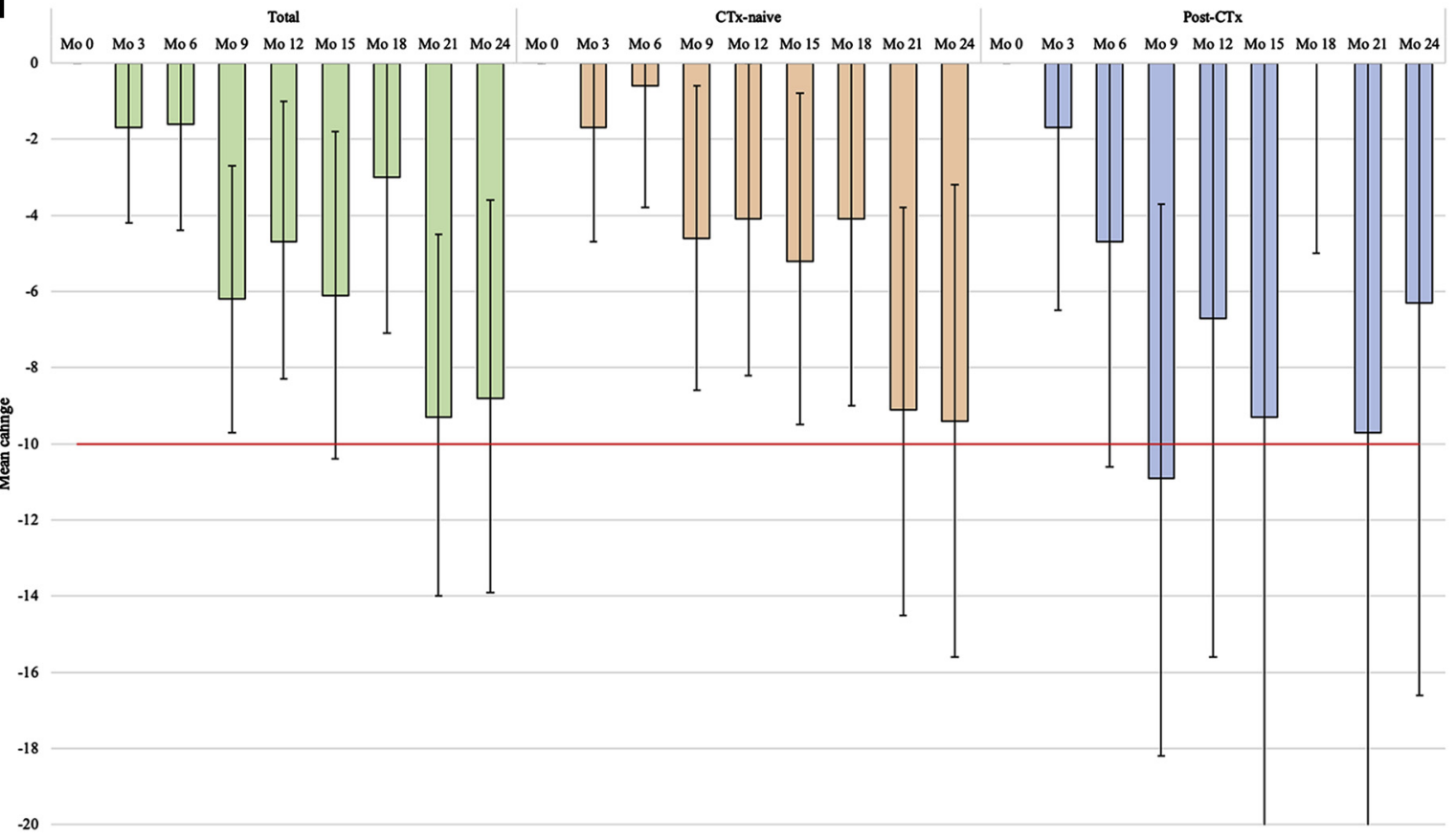

Abbreviations: CTx-naive $=$ No or no prior docetaxel chemotherapy at inclusion; post-CTx $=$ current or post-docetaxel chemotherapy at inclusion; HRQOL = health-related quality of life; MID = minimally important difference; VAS = visual analog scale. 


\section{Real-world Quality of Life in Castration-resistant Prostate Cancer}

Figure 3 continued

C Total

CTx-naive

post-CTx

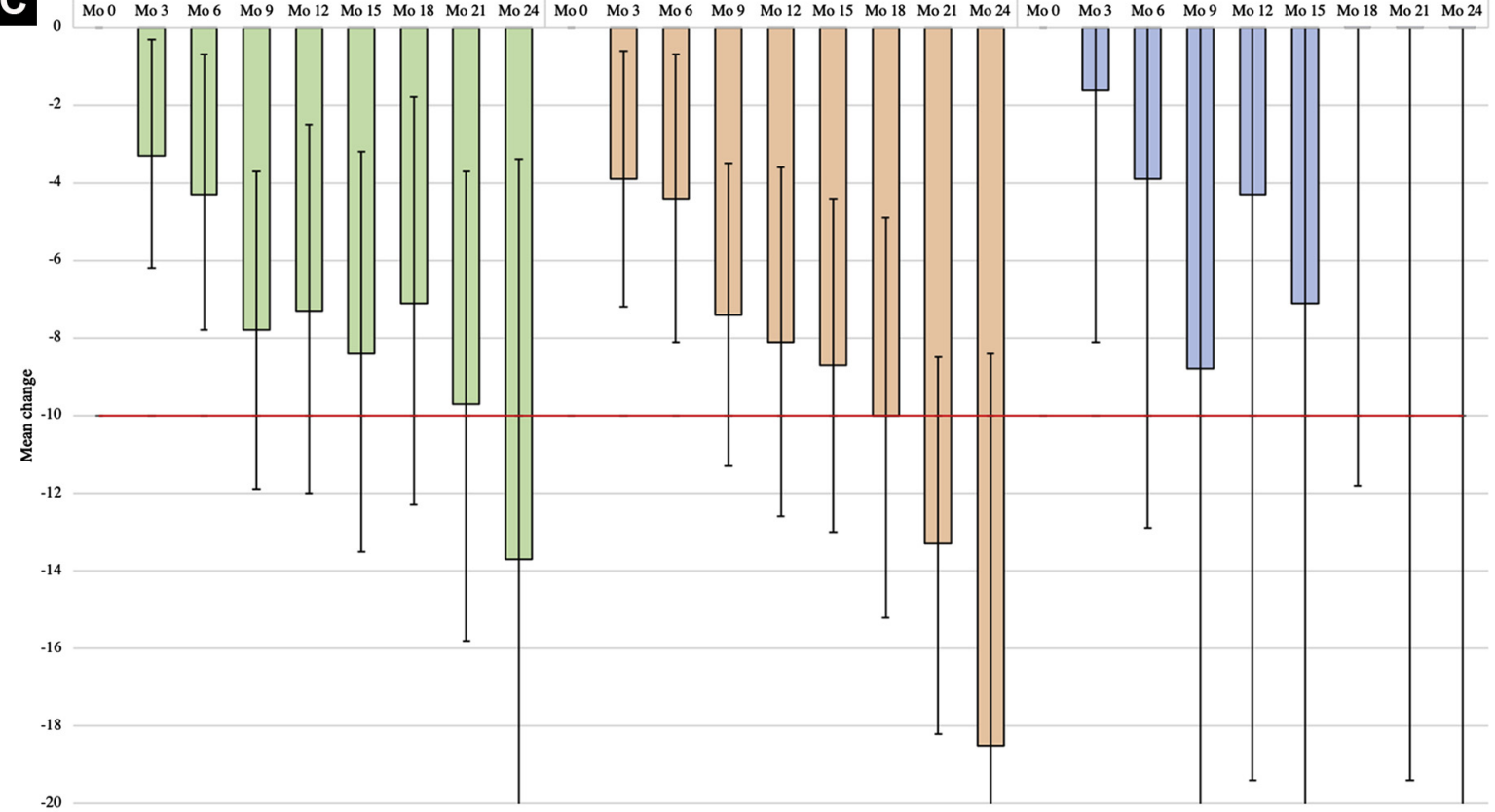

D

\begin{tabular}{|l|l|l|l|l|l|l|l} 
Total & CTx-naive & post-CTx
\end{tabular}

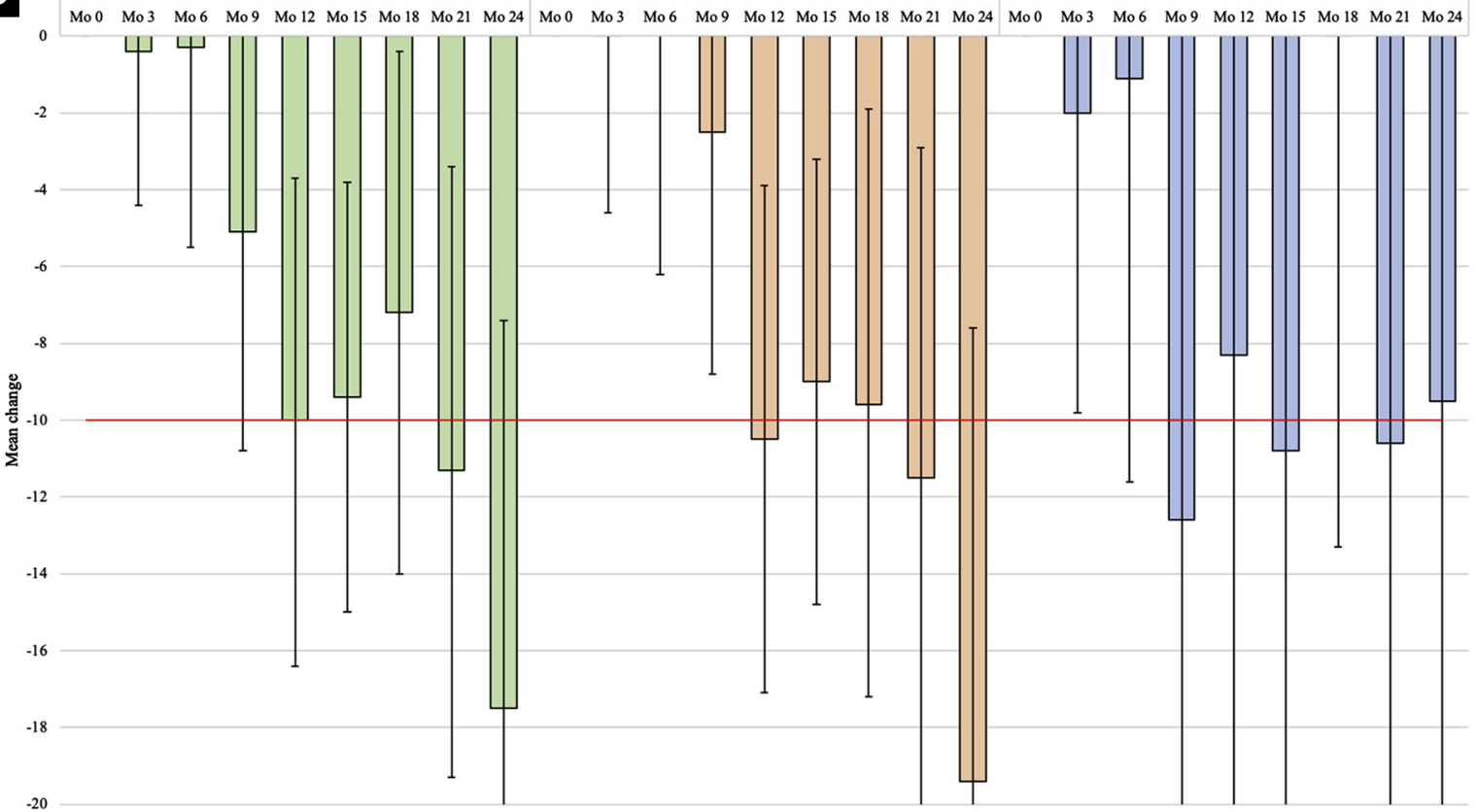

- We have shown that patients experienced most problems in role (ie, patient's ability to perform daily activities, leisure time, and/ or work) and physical functioning with pain, fatigue, and insomnia. Although $80 \%$ of our real-world population was treated with new drugs, HRQoL deteriorated over time, mainly on role and physical functioning.

- These results show the changes in HRQoL during mCRPC and highlight specific domains prone to deterioration. The start of 
E

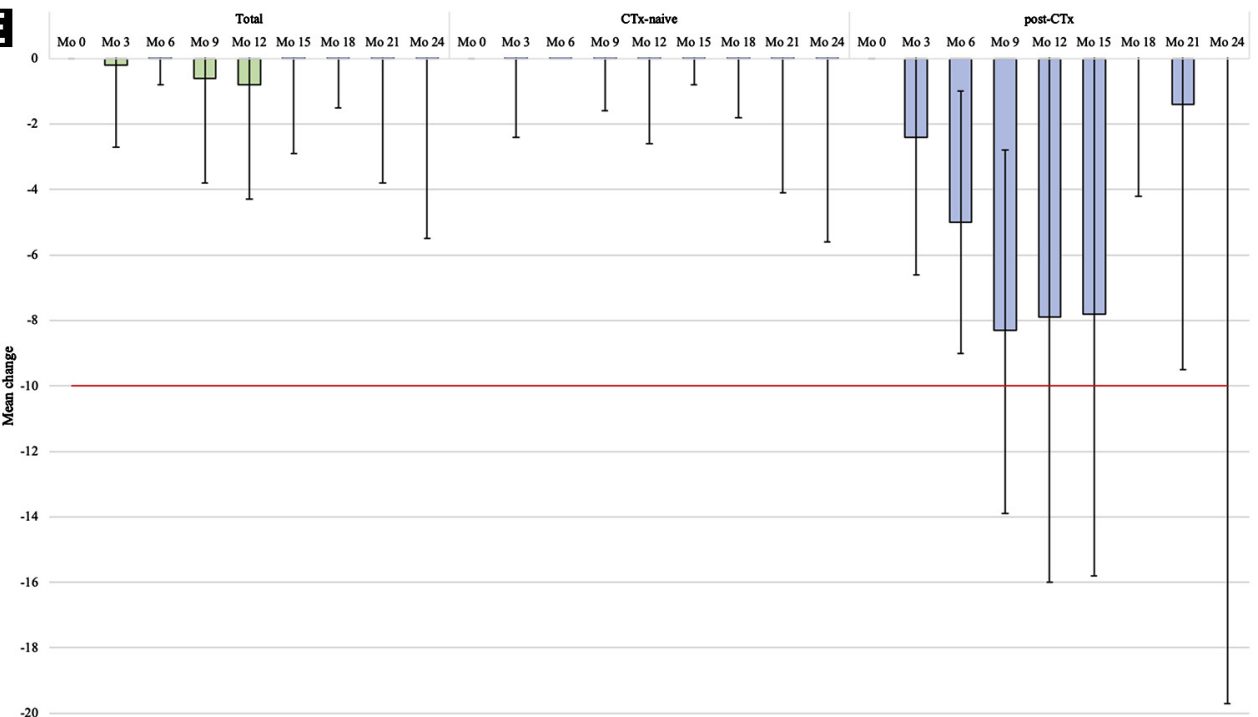

G

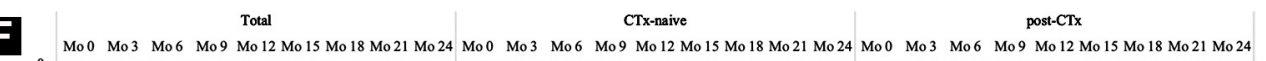

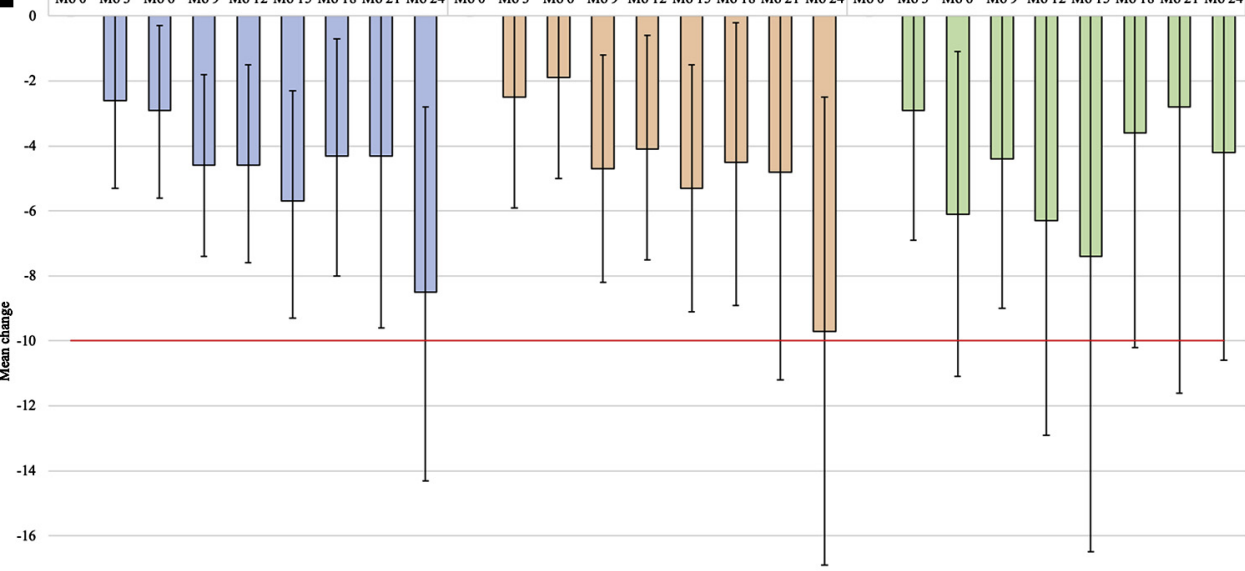

$-18$

$-20$

G

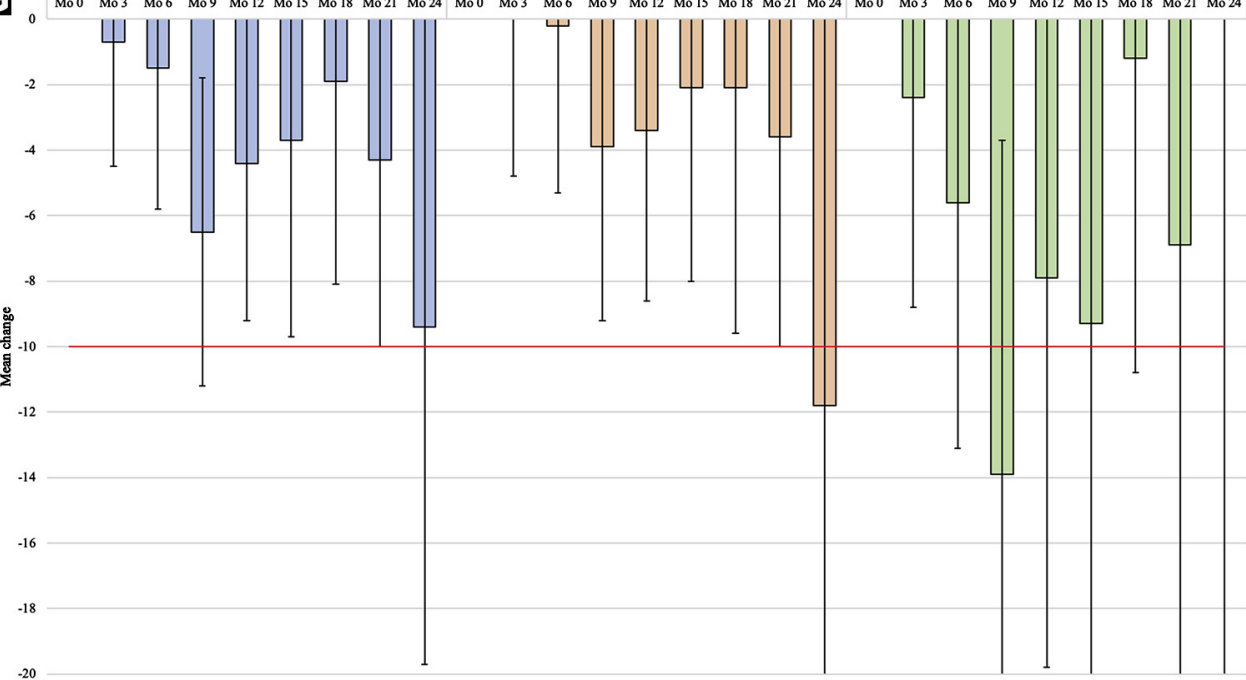




\section{Real-world Quality of Life in Castration-resistant Prostate Cancer}

Table 2 Proportion of Patients With a Clinically Relevant Deterioration in HRQ0L at Month 6 and Month 12

\begin{tabular}{|c|c|c|c|c|}
\hline & & Month 6 & Month 12 & $P$ Value \\
\hline Generic HRQoL (EQ-5D) & EQ VAS & $31 / 115$ (27.0) & 31/95 (32.6) & .281 \\
\hline \multirow{15}{*}{$\begin{array}{l}\text { Cancer-specific HRQoL (EORTC } \\
\text { QLQ-C30) }\end{array}$} & Global health status & 27/120 (22.5) & 32/96 (33.3) & .023 \\
\hline & Physical functioning & $38 / 115$ (33.0) & $37 / 90(41.1)$ & .170 \\
\hline & Role functioning & 36/117 (30.8) & 43/93 (46.2) & .009 \\
\hline & Emotional functioning & $15 / 119$ (12.6) & 19/95 (20.0) & .092 \\
\hline & Cognitive functioning & $37 / 119$ (31.1) & 33/95 (34.7) & .664 \\
\hline & Social functioning & 28/119 (23.5) & 33/95 (34.7) & .015 \\
\hline & Fatigue & $53 / 116(45.7)$ & 50/94 (53.2) & .064 \\
\hline & Nausea/vomiting & 15/119 (12.6) & 19/95 (20.0) & .359 \\
\hline & Pain & 26/119 (21.8) & 34/95 (35.8) & .002 \\
\hline & Dyspnea & 26/116 (22.4) & 16/93 (17.2) & .267 \\
\hline & Insomnia & 16/116 (13.8) & 20/94 (21.3) & .118 \\
\hline & Appetite loss & 24/118 (20.3) & 26/93 (28.0) & .286 \\
\hline & Constipation & 17/118 (14.4) & 17/94 (18.1) & .664 \\
\hline & Diarrhea & 20/117 (17.1) & 24/95 (25.3) & .152 \\
\hline & Financial difficulties & 8/118 (6.8) & 6/95 (6.3) & .688 \\
\hline \multirow{4}{*}{$\begin{array}{l}\text { Prostate cancer-specific HRQOL } \\
\text { (EORTC QLQ-PR25) }\end{array}$} & Sexual activity & $14 / 117(12.0)$ & 16/93 (17.2) & .180 \\
\hline & Urinary symptoms & 21/115 (18.3) & 22/94 (23.4) & .332 \\
\hline & Bowel symptoms & 11/93 (11.8) & $10 / 71(14.1)$ & .508 \\
\hline & $\begin{array}{l}\text { Hormonal therapy related } \\
\text { symptoms }\end{array}$ & 19/118 (16.1) & 24/94 (25.5) & .052 \\
\hline \multirow[t]{6}{*}{ Pain (BPI-SF) } & Pain severity & 9/75 (12.0) & $13 / 65$ (20.0) & .039 \\
\hline & Worst pain & 15/76 (19.7) & 21/65 (32.3) & .003 \\
\hline & Average pain & 10/74 (13.5) & 18/63 (28.6) & $<.001$ \\
\hline & Least pain & 9/73 (12.3) & 14/64 (21.9) & .118 \\
\hline & Current pain & $9 / 75(12.0)$ & 9/63 (14.3) & .289 \\
\hline & Pain & 7/61 (11.5) & 14/51 (27.5) & .004 \\
\hline
\end{tabular}

Data are presented as $\mathrm{n} / \mathrm{N}(\%)$ for total population $(\mathrm{N}=151)$.

$P$ values calculated for differences percentage of patients with MID at month 6 and month 12 .

Abbreviations: BPI-SF = Brief Pain Inventory-Short Form; CTX-naive = no or no prior docetaxel chemotherapy at inclusion; EORTC QLQ-C30 = European Organization for the Research and Treatment of Cancer Quality of Life Questionnaire; EORTC QLQ-PR25 = European Organization for the Research and Treatment of Cancer Quality of Life Questionnaire-Prostate Cancer Module; HRQOL = health-related quality of life; MID = minimal important difference; post-CTx = current or post-docetaxel chemotherapy at inclusion; VAS = visual analog scale.

best supportive care targeting these specific domains should be thought of in order to maintain HRQoL as long as possible.

\section{Acknowledgments}

This research was funded by the Netherlands Organization of Health Research and Development (ZonMW) with ZonMw project number 836011017 . The PRO-CAPRI study is a side study of the CAPRI registry. The CAPRI registry was funded by Sanofi-Aventis Netherlands B.V., Janssen-Cilag B.V., Astellas Pharma B.V., and Bayer B.V. The funding organizations had no role in the design and conduct of the study; collection, management, analysis, and interpretation of the data; and preparation, review, or approval of the manuscript.

\section{Disclosure}

W. Gerritsen and C. Uyl-de Groot had full access to all the data in the study and take responsibility for the integrity of the data and the accuracy of the data analysis.
M.C.P. Kuppen reports grants from the Netherlands Organization of Health Research and Development (ZonMW), SanofiAventis Netherlands B.V., Janssen-Cilag B.V., Astellas Pharma B.V., and Bayer B.V., during the conduct of the study and nonfinancial support from Ipsen, outside the submitted work. H.M. Westgeest reports grants from the Netherlands Organization of Health Research and Development (ZonMW), Sanofi-Aventis Netherlands B.V., Janssen-Cilag B.V., Astellas Pharma B.V., and Bayer B.V., during the conduct of the study; non-financial support from Ipsen; personal fees from Roche; personal fees and nonfinancial support from Sanofi; and non-financial support from Celgene, outside the submitted work. A.J.M. van den Eertwegh reports grants, personal fees, and non-financial support from Sanofi and Roche; personal fees and non-financial support from MSD Oncology and Pfizer; personal fees from Bristol-Myers Squibb, Amgen, Novartis, Ipsen, and Merck, outside the submitted work. J.L.L.M. Coenen reports personal fees from Sanofi, outside the submitted work. R.J.A. van Moorselaar reports personal fees from Amgen, Astellas, AstraZeneca, Bayer, Janssen, and Sanofi-Genzyme, 
Table 3 Time to Clinical Relevant Deterioration in Months of HRQoL for Total Population

\begin{tabular}{|c|c|c|c|}
\hline & & No. Events, \% & Time to MID, mos \\
\hline Generic HRQoL (EQ-5D) & EQ VAS & 59.6 & 10.8 (6-NR) \\
\hline \multirow{15}{*}{$\begin{array}{l}\text { Cancer-specific HRQoL (EORTC QLQ- } \\
\text { C30) }\end{array}$} & Global health status & 54.3 & $14.7(7-26)$ \\
\hline & Physical functioning & 58.9 & $13.1(6-26)$ \\
\hline & Role functioning & 60.3 & $12.2(4-28)$ \\
\hline & Emotional functioning & 33.8 & 26.6 (10-NR) \\
\hline & Cognitive functioning & 53.6 & $12.2(6-28)$ \\
\hline & Social functioning & 55.6 & 12.8 (7-NR) \\
\hline & Fatigue & 66.2 & $8.2(4-20)$ \\
\hline & Nausea/vomiting & 47.0 & 19.0 (9-NR) \\
\hline & Pain & 56.3 & $15.3(6-26)$ \\
\hline & Dyspnea & 43.0 & 22.6 (7-NR) \\
\hline & Insomnia & 41.1 & 22.6 (9-NR) \\
\hline & Appetite loss & 48.3 & 17.0 (9-NR) \\
\hline & Constipation & 38.4 & 24.5 (10-NR) \\
\hline & Diarrhea & 36.4 & NR (9-NR) \\
\hline & Financial difficulties & 17.9 & NR (26-NR) \\
\hline \multirow{6}{*}{$\begin{array}{l}\text { Prostate cancer-specific HRQoL } \\
\text { (EORTC QLQ-PR25) }\end{array}$} & Sexual activity & 13.9 & NR (NR-NR) \\
\hline & Sexual functioning & 2.0 & NR (NR-NR) \\
\hline & Urinary symptoms & 26.5 & NR (15-NR) \\
\hline & Bowel symptoms & 17.2 & NR (26-NR) \\
\hline & Incontinence aid & 5.3 & NR (NR-NR) \\
\hline & Hormonal therapy related symptoms & 27.8 & 26.3 (13-NR) \\
\hline \multirow[t]{6}{*}{ Pain $(\mathrm{BPI}-\mathrm{SF})^{\mathrm{a}}$} & Pain severity & 34.2 & NR (10-NR) \\
\hline & Worst pain & 46.8 & 15.9 (7-NR) \\
\hline & Average pain & 36.9 & NR (10-NR) \\
\hline & Least pain & 38.7 & NR (10-NR) \\
\hline & Current pain & 32.4 & NR (10-NR) \\
\hline & Pain interference & 31.5 & NR (13-NR) \\
\hline
\end{tabular}

Data are presented as percentages for number of events (ie, number of patients with MID) and median (IQR) for time to first MID in total population (N = 151).

Abbreviations: BPI-SF = Brief Pain Inventory-Short Form; CTX-naive = no or no prior docetaxel chemotherapy at inclusion; EORTC QLQ-C30 = European Organization for the Research and Treatment of Cancer Quality of Life Questionnaire; EORTC QLQ-PR25 = European Organization for the Research and Treatment of Cancer Quality of Life Questionnaire-Prostate Cancer Module; HRQL = healthrelated quality of life; IQR = interquartile range; MID = minimal important differences; NR = not reached; post-CTx = current or post-docetaxel chemotherapy at inclusion; VAS = visual analog scale. ${ }^{\mathrm{a} O n l y}$ patients with BPI-SF measurement at inclusion $(\mathrm{N}=111)$.

outside the submitted work. H.P. van den Berg reports personal fees from Janssen Cilag, Astellas, Bayer, and Ipsen, outside the submitted work. N. Mehra reports grants, personal fees and nonfinancial support from Astellas; grants and personal fees from Janssen and Roche; grants from Pfizer and Sanofi Genzyme, personal fees and non-financial support from MSD; and personal fees from BMS and Bayer, outside the submitted work. R. de Wit reports grants and personal fees from Sanofi and Bayer; and personal fees from Merck Sharp \& Dohme, Roche/Genentech, Janssen, and Clivis, outside the submitted work. I.M. van Oort reports grants and personal fees from Astellas, Janssen, and Bayer; and personal fees from Rocheand Mdx Health, outside the submitted work. W.R. Gerritsen reports grants from Bayer, MSD, Bristol-Myers Squibb, Astellas, Bayer, Sanofi, Amgen, Bayer, Astellas, and JanssenCilag, outside the submitted work. C.A. Uyl-de Groot reports grants from the Netherlands Organization of Health Research and Development (ZonMW), Sanofi-Aventis Netherlands B.V., Janssen-Cilag B.V., Astellas Pharma B.V., and Bayer B.V. during the conduct of the study; and grants from Boehringer Ingelheim, Astellas, Celgene, Sanofi, Janssen-Cilag, Bayer, Amgen, Genzyme, Merck, Glycostem Therapeutics, AstraZeneca, and Roche, outside the submitted work. The remaining authors have stated that they have no conflicts of interest.

\section{Supplemental Data}

Supplemental tables accompanying this article can be found in the online version at https://doi.org/10.1016/j.clgc.2019.11.015.

\section{References}

1. Kirby M, Hirst C, Crawford ED. Characterising the castration-resistant prostate cancer population: a systematic review. Int J Clin Pract 2011; 65:1180-92.

2. Tannock IF, de Wit R, Berry WR, et al, TAX 327 Investigators. Docetaxel plus prednisone or mitoxantrone plus prednisone for advanced prostate cancer. $N$ Engl J Med 2004; 351:1502-12.

3. de Bono JS, Oudard S, Ozguroglu M, et al, TROPIC Investigators. Prednisone plus cabazitaxel or mitoxantrone for metastatic castration-resistant prostate cancer progressing after docetaxel treatment: a randomised open-label trial. Lancet 2010; 376:1147-54. 


\section{Real-world Quality of Life in Castration-resistant Prostate Cancer}

4. Fizazi K, Scher HI, Molina A, et al, COU-AA-301 Investigators. Abiraterone acetate for treatment of metastatic castration-resistant prostate cancer: final overall survival analysis of the COU-AA-301 randomised, double-blind, placebocontrolled phase 3 study. Lancet Oncol 2012; 13:983-92.

5. Ryan CJ, Smith MR, de Bono JS, et al, COU-AA-302 Investigators. Abiraterone in metastatic prostate cancer without previous chemotherapy. N Engl J Med 2013; 368:138-48

6. Scher HI, Fizazi K, Saad F, et al, AFFIRM Investigators. Increased survival with enzalutamide in prostate cancer after chemotherapy. N Engl J Med 2012; 367: 1187-97.

7. Beer TM, Armstrong AJ, Rathkopf DE, et al, PREVAIL Investigators. Enzalutamide in metastatic prostate cancer before chemotherapy. N Engl J Med 2014;371:424-33.

8. Parker C, Nilsson S, Heinrich D, et al, ALSYMPCA Investigators. Alpha emitter radium-223 and survival in metastatic prostate cancer. N Engl J Med 2013; 369: 213-23.

9. Westgeest HM, Uyl-de Groot CA, van Moorselaar RJA, et al. Differences in trial and real-world populations in the Dutch Castration-resistant Prostate Cancer Registry. Eur Urol Focus 2018; 4:694-701.

10. Payne H, Pearcy R. Symptoms and health-related quality of life in castrationresistant prostate cancer: the patient's perspective. J Mens Health 2012; 9:9-16.

11. Sandblom G, Carlsson P, Sennfält K, Varenhorst E. A population-based study of pain and quality of life during the year before death in men with prostate cancer. $B r$ J Cancer 2004; 90:1163-8.

12. Sullivan PW, Mulani PM, Fishman M, Sleep D. Quality of life findings from a multicenter, multinational, observational study of patients with metastatic hormone-refractory prostate cancer. Qual Life Res 2007; 16:571-5.

13. James N, Eisenberger M, Fizazi K, et al. EQ-5D utility index in patients with metastatic castration-resistant prostate cancer (mCRPC) with progression during or after first-line docetaxel therapy. Value Health 2011; 14:A457-8.

14. Lloyd AJ, Kerr C, Penton J, Knerer G. Health-related quality of life and health utilities in metastatic castrate-resistant prostate cancer: a survey capturing experiences from a diverse sample of UK patients. Value Health 2015; 18:1152-7.

15. Melmed GY, Kwan L, Reid K, Litwin MS. Quality of life at the end of life: trends in patients with metastatic prostate cancer. Urology 2002; 59:103-9.

16. Litwin MS, Lubeck DP, Stoddard ML, Pasta DJ, Flanders SC, Henning JM. Quality of life before death for men with prostate cancer: results from the CaPSURE database. J Urol 2001; 165:871-5.

17. Beer TM, Miller K, Tombal B, et al. The association between health-related quality-of-life scores and clinical outcomes in metastatic castration-resistant prostate cancer patients: exploratory analyses of AFFIRM and PREVAIL studies. Eur J Cancer 2017; 87:21-9.

18. Basch E, Autio K, Ryan CJ, et al. Abiraterone acetate plus prednisone versus prednisone alone in chemotherapy-naive men with metastatic castration-resistant prostate cancer: patient-reported outcome results of a randomised phase 3 trial. Lancet Oncol 2013; 14:1193-9.

19. Loriot Y, Miller K, Sternberg CN, et al. Effect of enzalutamide on health-related quality of life, pain, and skeletal-related events in asymptomatic and minimally symptomatic, chemotherapy-naive patients with metastatic castration-resistant prostate cancer (PREVAIL): results from a randomised, phase 3 trial. Lancet Oncol 2015; 16:509-21.

20. Fizazi K, Scher HI, Miller K, et al. Effect of enzalutamide on time to first skeletalrelated event, pain, and quality of life in men with castration-resistant prostate cancer: results from the randomised, phase 3 AFFIRM trial. Lancet Oncol 2014 $15: 1147-56$.
21. Bahl A, Oudard S, Tombal B, et al, TROPIC Investigators. Impact of cabazitaxel on 2-year survival and palliation of tumour-related pain in men with metastatic castration-resistant prostate cancer treated in the TROPIC trial. Ann Oncol 2013; 24:2402-8.

22. Kotronoulas G, Kearney N, Maguire R, et al. What is the value of the routine use of patient-reported outcome measures toward improvement of patient outcomes, processes of care, and health service outcomes in cancer care? A systematic review of controlled trials. J Clin Oncol 2014; 32:1480-501.

23. Versteegh MM, Vermeulen KM, Evers SM, de Wit GA, Prenger R, Stolk EA. Dutch tariff for the five-level version of EQ-5D. Value Health 2016; 19:343-52.

24. EuroQol Research Foundation. EQ-5D-5L User Guide 2019, Available at: https:// euroqol.org/publications/user-guides. Accessed: April 1, 2018.

25. Scott NW, Fayers P, Aaronson NK, et al. EORTC QLQ-C30 Reference Values Manual. 2nd ed. Brussels, Belgium: EORTC Quality of Life Group; 2008.

26. van Andel G, Bottomley A, Fosså SD, et al. An international field study of the EORTC QLQ-PR25: a questionnaire for assessing the health-related quality of life of patients with prostate cancer. Eur J Cancer 2008; 44:2418-24.

27. Cleeland CS, Ryan KM. Pain assessment: global use of the Brief Pain Inventory. Ann Acad Med Singapore 1994; 23:129-38.

28. Pickard AS, Neary MP, Cella D. Estimation of minimally important differences in EQ-5D utility and VAS scores in cancer. Health Qual Life Outcomes 2007; 5:70.

29. Nussbaum N, George D, Abernethy A, et al. Patient experience in the treatment of metastatic castration-resistant prostate cancer: state of the science. Prostate Cancer Prostatic Dis 2016; 19:111-21.

30. Osoba D, Rodrigues G, Myles J, Zee B, Pater J. Interpreting the significance of changes in health-related quality-of-life scores. J Clin Oncol 1998; 16:139-44.

31. Central Bureauof Statistics (CBS). Standaard Onderwijsindeling 2016, Available at: https://www.cbs.nl/nl-nl/onze-diensten/methoden/classificaties/onderwijs-enberoepen/standaard-onderwijsindeling-soi-/standaard-onderwijsindeling-2016. Accessed: February 22, 2018.

32. Torvinen S, Färkkilä N, Sintonen H, Saarto T, Roine RP, Taari K. Health-related quality of life in prostate cancer. Acta Oncol (Madr) 2013; 52:1094-101.

33. Feng Y, Herdman M, van Nooten F, et al. An exploration of differences between Japan and two European countries in the self-reporting and valuation of pain and discomfort on the EQ-5D. Qual Life Res 2017; 26:2067-78.

34. Bernert S, Fernández A, Haro JM, et al, ESEMeD/MHEDEA 2000 Investigators. Comparison of different valuation methods for population health status measured by the EQ-5D in three European countries. Value Health 2009; 12:750-8.

35. Hinz A, Singer S, Brähler E. European reference values for the quality of life questionnaire EORTC QLQ-C30: results of a German investigation and a summarizing analysis of six European general population normative studies. Acta Oncol (Madr) 2014; 53:958-65.

36. Rathkopf DE, Smith MR, de Bono JS, et al. Updated interim efficacy analysis and long-term safety of abiraterone acetate in metastatic castration-resistant prostate cancer patients without prior chemotherapy (COU-AA-302). Eur Urol 2014; 66: $815-25$.

37. Logothetis CJ, Basch E, Molina A, et al. Effect of abiraterone acetate and prednisone compared with placebo and prednisone on pain control and skeletal-related events in patients with metastatic castration-resistant prostate cancer: exploratory analysis of data from the COU-AA-301 randomised trial. Lancet Oncol 2012; 13: $1210-7$.

38. Downing A, Wright P, Hounsome L, et al. Quality of life in men living with advanced and localised prostate cancer in the UK: a population-based study. Lancet Oncol 2019; 20:436-47. 


\section{Supplemental Data}

Supplemental Table 1 Overview of Used Questionnaires and MID

\begin{tabular}{|c|c|c|c|c|}
\hline & No. Items & No. Items Needed ${ }^{a}$ & Scale & MID \\
\hline$E Q-5 D^{28,29}$ & - & & - & - \\
\hline EQ VAS & 1 & 1 & $0-100$ & $7-11$ \\
\hline$E Q-5 D$ index value & 5 & 5 & -0.594 to 1 & - \\
\hline \multicolumn{5}{|l|}{ EORTC QLQ-C30 ${ }^{29,30}$} \\
\hline Physical functioning ${ }^{\mathrm{b}}$ & 5 & 3 & $0-100$ & 10 \\
\hline Role functioning ${ }^{b}$ & 2 & 1 & $0-100$ & 10 \\
\hline Emotional functioning ${ }^{b}$ & 4 & 2 & $0-100$ & 10 \\
\hline Cognitive functioning ${ }^{b}$ & 2 & 1 & $0-100$ & 10 \\
\hline Social functioning ${ }^{b}$ & 2 & 1 & $0-100$ & 10 \\
\hline Fatigue $^{c}$ & 3 & 2 & $0-100$ & 10 \\
\hline Nausea/vomiting ${ }^{\mathrm{C}}$ & 2 & 1 & $0-100$ & 10 \\
\hline Pain $^{C}$ & 2 & 1 & $0-100$ & 10 \\
\hline Dyspnea $^{\mathrm{C}}$ & 1 & 1 & $0-100$ & 10 \\
\hline Insomnia $^{c}$ & 1 & 1 & $0-100$ & 10 \\
\hline Appetite loss $^{\mathrm{C}}$ & 1 & 1 & $0-100$ & 10 \\
\hline Constipation $^{c}$ & 1 & 1 & $0-100$ & 10 \\
\hline Diarrhea $^{\mathrm{C}}$ & 1 & 1 & $0-100$ & 10 \\
\hline Financial difficulties ${ }^{C}$ & 1 & 1 & $0-100$ & 10 \\
\hline \multicolumn{5}{|l|}{ EORTC QLQ-PR25 ${ }^{29}$} \\
\hline Sexual activity ${ }^{b}$ & 2 & 1 & $0-100$ & 10 \\
\hline Sexual functioning ${ }^{b}$ & 4 & 2 & $0-100$ & 10 \\
\hline Urinary symptoms $^{\mathrm{C}}$ & 8 & 4 & $0-100$ & 10 \\
\hline Bowel symptoms ${ }^{c}$ & 4 & 2 & $0-100$ & 10 \\
\hline $\begin{array}{l}\text { Hormonal therapy-related } \\
\text { symptoms }{ }^{C}\end{array}$ & 6 & 3 & $0-100$ & 10 \\
\hline Use of incontinence aid ${ }^{C}$ & 1 & 1 & $0-100$ & 10 \\
\hline \multicolumn{5}{|l|}{ BPI-SF $^{27,29}$} \\
\hline Pain severity & 4 & 4 & $0-10$ & $\begin{array}{c}\geq 30 \% \text { and } \geq 2 \text { points from } \\
\text { baseline }\end{array}$ \\
\hline Worst pain & 1 & 1 & $0-10$ & $\begin{array}{c}\geq 30 \% \text { and } \geq 2 \text { points from } \\
\text { baseline }\end{array}$ \\
\hline Least pain & 1 & 1 & $0-10$ & $\begin{array}{c}\geq 30 \% \text { and } \geq 2 \text { points from } \\
\text { baseline }\end{array}$ \\
\hline Average pain & 1 & 1 & $0-10$ & $\begin{array}{c}\geq 30 \% \text { and } \geq 2 \text { points from } \\
\text { baseline }\end{array}$ \\
\hline Current pain & 1 & 1 & $0-10$ & $\begin{array}{c}\geq 30 \% \text { and } \geq 2 \text { points from } \\
\text { baseline }\end{array}$ \\
\hline Pain interference & 7 & 4 & $0-10$ & $\begin{array}{c}\geq 50 \% \text { of baseline standard } \\
\text { deviation and } \geq 2 \text { points }\end{array}$ \\
\hline
\end{tabular}

Abbreviations: BPI-SF = Brief Pain Inventory-Short Form; EORTC QLQ-C30 = European Organization for the Research and Treatment of Cancer Quality of Life Questionnaire; EORTC QLQ-PR25 = European Organization for the Research and Treatment of Cancer Quality of Life Questionnaire-Prostate Cancer Module; MID = minimally important difference; VAS = visual analog scale.

aThe number of items per domain needed to be completed to adequately calculate the score per domain.

${ }^{b}$ Functional scales (high scores indicate high level of functioning).

'Symptom scales (high scores indicate high symptom burden). 


\section{Real-world Quality of Life in Castration-resistant Prostate Cancer}

Supplemental Table 2 Compliance Rate With HRQoL Questionnaires

\begin{tabular}{l|c|c|c|c|c|}
$\begin{array}{l}\text { Months After } \\
\text { Inclusion }\end{array}$ & Total & EQ-5D & EORTC QLQ-C30 & EORTC QLQ-PR25 & BPI-SF $^{\text {a }}$ \\
0 & 151 & $150(99)$ & $146(97)$ & $145(96)$ & $111(74)$ \\
3 & 136 & $133(98)$ & $134(99)$ & - & $107(79)$ \\
6 & 124 & $122(98)$ & $123(99)$ & $120(97)$ & $99(80)$ \\
\hline 9 & 119 & $118(99)$ & $118(99)$ & - & $103(87)$ \\
12 & 101 & $98(97)$ & $98(97)$ & $96(95)$ & $71(84)$ \\
15 & 83 & $81(98)$ & $82(99)$ & - & $57(81)$ \\
18 & 70 & $70(100)$ & $70(100)$ & $66(94)$ & - \\
\hline 21 & 55 & $55(100)$ & $55(100)$ & $30(91)$ & $34(87)$ \\
\hline
\end{tabular}

Compliance rate $=$ the number of patients completing at least one question divided by the total number of available patients per time point (ie, alive and still on study). All data are presented as $n(\%)$.

Abbreviations: BPI-SF = Brief Pain Inventory-Short Form; EORTC QLQ-C30 = European Organization for the Research and Treatment of Cancer Quality of Life Questionnaire; EORTC QLQ-PR25 = European Organization for the Research and Treatment of Cancer Quality of Life Questionnaire-Prostate Cancer Module; HRQoL = health-related quality of life.

aBPI-SF was added 1 year after study start through protocol amendment: $27 \%$ of patients was enrolled before protocol amendment. 
Malou C.P. Kuppen et al

Supplemental Table 3 Representativeness of PRO-CAPRI Population Based on Baseline Characteristics

\begin{tabular}{|c|c|c|c|}
\hline & PRO-CAPRI, N = 151 & CAPRI, $N=3616$ & $P$ Value \\
\hline \multicolumn{4}{|l|}{ Age, y } \\
\hline Median (range) & $72(54-94)$ & 75 (46-99) & .002 \\
\hline$\geq 75 y, \%$ & 41 & 52 & .006 \\
\hline ECOG performance score, \% & & & .078 \\
\hline 0 & 30 & 18 & \\
\hline 1 & 21 & 18 & \\
\hline$>1$ & 3 & 5 & \\
\hline Unknown & 46 & 60 & \\
\hline Gleason score, \% & & & .602 \\
\hline$\leq 7$ & 34 & 34 & \\
\hline $8-10$ & 56 & 51 & \\
\hline No histology & 3 & 3 & \\
\hline Metastasis biopsy & 1 & 1 & \\
\hline Unknown & 6 & 10 & \\
\hline Charlson comorbidity index, \% & & & .211 \\
\hline 6 & 70 & 62 & \\
\hline $7-8$ & 26 & 32 & \\
\hline $9-10$ & 4 & 5 & \\
\hline$>10$ & 1 & 2 & \\
\hline Unknown & 0 & 0 & \\
\hline \multicolumn{4}{|l|}{ Disease state, $\%$} \\
\hline $\mathrm{N} 1 / \mathrm{NO} / \mathrm{Nx}$ & $5 / 46 / 49$ & $7 / 28 / 65$ & .020 \\
\hline M1/MO/Mx (bone) & 6/62/33 & 9/53/39 & .144 \\
\hline M1/M0/Mx (visceral) & $14 / 3 / 83$ & $16 / 4 / 81$ & 1.000 \\
\hline Period from castration to $\mathrm{mCRPC}$, mos & & & .986 \\
\hline Median (IQR) & $15.1(9-28)$ & $15.1(8-29)$ & \\
\hline Unknown, \% & 0 & $<1$ & \\
\hline Hemoglobin, mmol/L & & & .014 \\
\hline Median (IQR) & $8.3(7.6-8.8)$ & $8.0(7.3-8.6)$ & \\
\hline Unknown, \% & 30 & 34 & \\
\hline Lactate dehydrogenase, U/L & & & .058 \\
\hline Median (IQR) & $212(184-249)$ & $223(188-294)$ & \\
\hline Unknown, \% & 47 & 59 & \\
\hline Alkaline phosphatase, U/L & & & .041 \\
\hline Median (IQR) & $97(75-150)$ & $106(78-192)$ & \\
\hline Unknown, \% & 30 & 37 & \\
\hline Prostate-specific antigen, $\mu \mathrm{g} / \mathrm{L}$ & & & .247 \\
\hline Median (IQR) & $15.0(5-44)$ & $16.7(6-62)$ & \\
\hline Unknown, \% & 1 & 3 & \\
\hline Treatment during follow-up, \% & & & $<.001$ \\
\hline None & 1 & 12 & \\
\hline No LPD & 5 & 25 & \\
\hline LPD & 94 & 63 & \\
\hline Docetaxel & 66 & 43 & $<.001$ \\
\hline Cabazitaxel & 25 & 13 & $<.001$ \\
\hline Abiraterone & 38 & 32 & .106 \\
\hline Enzalutamide & 72 & 30 & $<.001$ \\
\hline Radium-223 & 17 & 8 & $<.001$ \\
\hline
\end{tabular}

All baseline measurements were included if they were measured in the period of 3 months prior or 3 months after mCRPC diagnosis.

Tested for statistical significance between the PRO-CAPRI subgroup and the rest of CAPRI-population $(\mathrm{N}=3465)$.

Abbreviations: $\mathrm{ADT}=$ Androgen deprivation therapy; $\mathrm{CTX}$-naive = no or no prior docetaxel chemotherapy at inclusion; $\mathrm{ECOG}=$ Eastern Cooperative Oncology Group; IQR = interquartile range; $\mathrm{LPD}=$ life prolonging drug (either docetaxel, cabazitaxel, abiraterone, enzalutamide or radium-223); mCRPC = metastastic castration-resistant prostate cancer; post-CTx = current or post-docetaxel chemotherapy at inclusion. 


\section{Real-world Quality of Life in Castration-resistant Prostate Cancer}

Supplemental Table 4 Assessment of HRQoL With Subgroups per Disease State at Inclusion

\begin{tabular}{|c|c|c|c|c|c|}
\hline & & Total $N=151$ & CTx-naive $\mathrm{N}=112$ & Post-CTx N $=39$ & $P$ Value \\
\hline \multirow[t]{7}{*}{ Generic HRQoL (EQ-5D) } & Mobility, ${ }^{\mathrm{a}}$ & 48 & 47 & 49 & .775 \\
\hline & Self-care, $\%^{a}$ & 15 & 16 & 10 & .404 \\
\hline & Usual activities, ${ }^{\mathrm{a}}$ & 43 & 43 & 44 & .774 \\
\hline & Pain/discomfort, $\%^{a}$ & 55 & 46 & 51 & .698 \\
\hline & Anxiety/depression, ${ }^{a}$ & 27 & 28 & 23 & .630 \\
\hline & EQ VAS & $73.2(17)$ & $72.9(17)$ & $73.9(16)$ & .848 \\
\hline & $E Q-5 D$ index value & $0.82(0.17)$ & $0.82(0.16)$ & $0.82(0.16)$ & .796 \\
\hline \multirow{15}{*}{$\begin{array}{l}\text { Cancer-specific HRQoL } \\
\text { (EORTC QLQ-C30) }\end{array}$} & Global health status & $75.9(17)$ & $75.5(18)$ & $76.9(12)$ & .954 \\
\hline & Physical functioning & $76.1(23)$ & $75.8(24)$ & $76.8(23)$ & .972 \\
\hline & Role functioning & $69.3(32)$ & $68.8(32)$ & $71.0(30)$ & .853 \\
\hline & Emotional functioning & $82.8(18)$ & $80.9(19)$ & $88.4(14)$ & .022 \\
\hline & Cognitive functioning & $85.4(18)$ & $84.7(18)$ & $87.5(17)$ & .455 \\
\hline & Social functioning & $80.5(27)$ & $78.9(29)$ & $85.2(21)$ & .405 \\
\hline & Fatigue & $32.3(25)$ & $32.6(26)$ & $31.6(21)$ & .963 \\
\hline & Nausea/vomiting & $5.5(15)$ & $5.9(17)$ & $4.2(10)$ & .770 \\
\hline & Pain & $23.4(25)$ & $25.2(26)$ & $18.1(20)$ & .243 \\
\hline & Dyspnea & $18.9(27)$ & $18.2(26)$ & $21.3(28)$ & .516 \\
\hline & Insomnia & $22.8(28)$ & $24.3(28)$ & $18.5(27)$ & .235 \\
\hline & Appetite loss & $11.0(25)$ & $10.4(24)$ & $13.0(27)$ & .490 \\
\hline & Constipation & $12.8(22)$ & $14.8(24)$ & $6.5(13)$ & .083 \\
\hline & Diarrhea & $10.0(23)$ & $9.4(23)$ & $12.0(23)$ & .260 \\
\hline & Financial difficulties & 4.6 (14) & $5.2(14)$ & $2.8(12)$ & .203 \\
\hline \multirow{6}{*}{$\begin{array}{l}\text { Prostate cancer-specific } \\
\text { HRQoL (EORTC QLQ- } \\
\text { PR25) }\end{array}$} & Sexual activity & $6.7(16)$ & $8.5(18)$ & $1.4(5)$ & .016 \\
\hline & Sexual functioning ${ }^{\mathrm{b}}$ & $55.2(22)$ & $58.3(18)$ & $45.0(33)$ & .246 \\
\hline & Urinary symptoms & $21.1(17)$ & 22.7 (18) & $16.4(14)$ & .057 \\
\hline & Bowel symptoms & $7.4(14)$ & $8.9(16)$ & $3.7(8)$ & .038 \\
\hline & Incontinence aid ${ }^{C}$ & $13.3(29)$ & $14.7(23)$ & $9.1(22)$ & .407 \\
\hline & $\begin{array}{c}\text { Hormonal therapy related } \\
\text { symptoms }\end{array}$ & $16.6(13)$ & $16.9(14)$ & $15.8(10)$ & .980 \\
\hline \multirow[t]{6}{*}{ Pain (BPI-SF) } & Pain severity & & & & \\
\hline & Worst pain & $2.22(2)$ & $2.21(3)$ & $2.24(2)$ & .530 \\
\hline & Average pain & $1.82(2)$ & $1.89(2)$ & $1.58(2)$ & .960 \\
\hline & Least pain & $1.11(2)$ & $1.12(2)$ & $1.08(2)$ & .858 \\
\hline & Current pain & $1.52(2)$ & $1.67(2)$ & $0.96(1)$ & .407 \\
\hline & Pain interference & $1.73(2)$ & $1.82(2)$ & $1.42(2)$ & .492 \\
\hline
\end{tabular}

All data are presented as mean (SD) unless listed otherwise.

Percentages can exceed $100 \%$ owing to rounding.

$P$ values calculated for differences in time to first MID between CTx-naive and post-CTx patients.

Abbreviations: BPI-SF = Brief Pain Inventory-Short Form; CTX-naive $=$ no or no prior docetaxel chemotherapy at inclusion; EORTC QL Q-C30 = European Organization for the Research and Treatment of Cancer Quality of Life Questionnaire; EORTC QLQ-PR25 = European Organization for the Research and Treatment of Cancer Quality of Life Questionnaire-Prostate Cancer Module; HRQOL = health-related quality of life; post-CTX = current or post-docetaxel chemotherapy at inclusion; SD = standard deviation; VAS = visual analog scale.

aPercentage of patients reporting any problems (level 2 to 5 )

${ }^{\mathrm{b}}$ Mean scores of patients reporting any sexual activity.

'Mean scores of patients reporting any use of incontinence aid. 
Malou C.P. Kuppen et al

Supplemental Table 5a Proportion of CTx-naive Patients With a Clinically Relevant Deterioration and Time to Deterioration in HRQoL at Month 6 and Month 12

\begin{tabular}{|c|c|c|c|c|}
\hline & & Month 6 & Month 12 & $P$ Value \\
\hline Generic HRQoL (EQ-5D) & EQ VAS & 22/85 (25.9) & 23/73 (31.5) & .556 \\
\hline \multirow{15}{*}{$\begin{array}{l}\text { Cancer-specific HRQOL (EORTC } \\
\text { QLQ-C30) }\end{array}$} & Global health status & $16 / 90(17.8)$ & $24 / 75(32.0)$ & .027 \\
\hline & Physical functioning & $23 / 85(27.1)$ & $30 / 69(43.5)$ & .019 \\
\hline & Role functioning & 24/88 (27.3) & $33 / 73$ (45.2) & .017 \\
\hline & Emotional functioning & $8 / 89(9.0)$ & $13 / 74(17.6)$ & .096 \\
\hline & Cognitive functioning & 27/89 (30.3) & $27 / 74(36.5)$ & .302 \\
\hline & Social functioning & 17/89 (19.1) & $26 / 74(35.1)$ & .007 \\
\hline & Fatigue & $38 / 86(44.2)$ & $39 / 73(53.4)$ & .096 \\
\hline & Nausea/vomiting & 12/89 (13.5) & 13/74 (17.6) & .791 \\
\hline & Pain & 18/89 (20.2) & 25/74 (33.8) & .019 \\
\hline & Dyspnea & 20/86 (23.3) & $14 / 72(19.4)$ & .549 \\
\hline & Insomnia & 13/86 (15.1) & 16/73 (21.9) & .227 \\
\hline & Appetite loss & 19/88 (21.6) & 21/72 (29.2) & .302 \\
\hline & Constipation & 14/88 (15.9) & $15 / 73(20.5)$ & .648 \\
\hline & Diarrhea & 15/87 (17.2) & $20 / 74(27.0)$ & .238 \\
\hline & Financial difficulties & 6/88 (6.8) & $6 / 74(8.1)$ & .688 \\
\hline \multirow{4}{*}{$\begin{array}{l}\text { Prostate cancer-specific HRQoL } \\
\text { (EORTC QLQ-PR25) }\end{array}$} & Sexual activity & $12 / 86(14.0)$ & $16 / 71$ (22.5) & .070 \\
\hline & Urinary symptoms & 16/83 (19.3) & $18 / 71$ (25.4) & .424 \\
\hline & Bowel symptoms & 10/66 (15.2) & $8 / 52$ (15.4) & .688 \\
\hline & $\begin{array}{l}\text { Hormonal therapy related } \\
\text { symptoms }\end{array}$ & 11/87 (12.6) & 18/72 (25.0) & .035 \\
\hline \multirow[t]{6}{*}{ Pain (BPI-SF) } & Pain severity & $6 / 56(10.7)$ & $9 / 52(17.3)$ & .219 \\
\hline & Worst pain & 10/57 (17.5) & $15 / 52$ (28.8) & .039 \\
\hline & Average pain & $7 / 56(12.5)$ & $12 / 51$ (23.5) & .016 \\
\hline & Least pain & $7 / 54$ (13.0) & $11 / 51(21.6)$ & .267 \\
\hline & Current pain & $6 / 57$ (10.5) & $5 / 50(10.0)$ & 1.000 \\
\hline & Pain interference & $5 / 46(10.9)$ & 11/42 (26.2) & .008 \\
\hline
\end{tabular}

Data are presented as $\mathrm{n} / \mathrm{N}(\%)$ for total population $(\mathrm{N}=112)$.

$P$ values calculated for differences between proportion of patients with MID at month 6 and month 12 .

Abbreviations: BPI-SF = Brief Pain Inventory-Short Form; CTX-naive = no or no prior docetaxel chemotherapy at inclusion; EORTC QLQ-C30 = European Organization for the Research and Treatment of Cancer Quality of Life Questionnaire; EORTC QLQ-PR25 = European Organization for the Research and Treatment of Cancer Quality of Life Questionnaire-Prostate Cancer Module; HRQL = healthrelated quality of life; MID = minimal important difference; VAS = visual analog scale. 


\section{Real-world Quality of Life in Castration-resistant Prostate Cancer}

Supplemental Table 5b Proportion of Post-CTx Patients With a Clinically Relevant Deterioration and Time to Deterioration in HRQ0L at Month 6 and Month 12

\begin{tabular}{|c|c|c|c|c|}
\hline & & Month 6 & Month 12 & $P$ Value \\
\hline Generic HRQOL (EQ-5D) & EQ VAS & $9 / 30(30.0)$ & 8/22 (36.4) & .375 \\
\hline \multirow{15}{*}{$\begin{array}{l}\text { Cancer-specific HRQoL (EORTC } \\
\text { QLQ-C30) }\end{array}$} & Global health status & $11 / 30(36.7)$ & 8/21 (38.1) & 1.000 \\
\hline & Physical functioning & $15 / 30(50.0)$ & 7/21 (33.3) & .453 \\
\hline & Role functioning & $12 / 29(41.4)$ & $10 / 20(50.0)$ & .453 \\
\hline & Emotional functioning & $7 / 30$ (23.3) & 6/21 (28.6) & .688 \\
\hline & Cognitive functioning & 10/30 (33.3) & 6/21 (28.6) & .688 \\
\hline & Social functioning & $11 / 30(36.7)$ & 7/21 (33.3) & 1.000 \\
\hline & Fatigue & $15 / 30(50.0)$ & $11 / 21(52.4)$ & .688 \\
\hline & Nausea/vomiting & $3 / 30(10.0)$ & 6/21 (28.6) & .375 \\
\hline & Pain & $8 / 30(26.7)$ & $9 / 21(42.9)$ & .063 \\
\hline & Dyspnea & $6 / 30(20.0)$ & 2/21 (9.5) & .500 \\
\hline & Insomnia & $3 / 30(10.0)$ & 4/21 (19.0) & .625 \\
\hline & Appetite loss & $5 / 30(16.7)$ & $5 / 21(23.8)$ & 1.000 \\
\hline & Constipation & $3 / 30(10.0)$ & 2/21 (9.5) & 1.000 \\
\hline & Diarrhea & $5 / 30(16.7)$ & 4/31 (19.0) & .688 \\
\hline & Financial difficulties & $2 / 30(6.7)$ & $0 / 21(0.0)$ & 1.000 \\
\hline \multirow{4}{*}{$\begin{array}{l}\text { Prostate cancer-specific HRQLL } \\
\text { (EORTC QLQ-PR25) }\end{array}$} & Sexual activity & 2/31 (6.5) & $0 / 22(0.0)$ & 1.000 \\
\hline & Urinary symptoms & $5 / 32(15.6)$ & 4/23 (17.4) & 1.000 \\
\hline & Bowel symptoms & $1 / 27(3.7)$ & 2/19 (10.5) & 1.000 \\
\hline & $\begin{array}{l}\text { Hormonal therapy related } \\
\text { symptoms }\end{array}$ & 8/31 (25.8) & 6/22 (27.3) & 1.000 \\
\hline \multirow[t]{6}{*}{ Pain (BPI-SF) } & Pain severity & $3 / 19(15.8)$ & $4 / 13(30.8)$ & .250 \\
\hline & Worst pain & $5 / 19$ (26.3) & 6/13 (46.2) & .125 \\
\hline & Average pain & $3 / 18(16.7)$ & $6 / 12(50.0)$ & .063 \\
\hline & Least pain & 2/19 (10.5) & $3 / 13(23.1)$ & .500 \\
\hline & Current pain & $3 / 18$ (16.7) & 4/13 (30.8) & .250 \\
\hline & Pain interference & 2/15 (13.3) & 3/9 (33.3) & 1.000 \\
\hline
\end{tabular}

Data are presented as $\mathrm{n} / \mathrm{N}(\%)$ for CTx-naive population $(\mathrm{N}=39)$.

$P$ values calculated for differences between proportion of patients with MID at month 6 and month 12

Abbreviations: BPI-SF = Brief Pain Inventory-Short Form; EORTC QLQ-C30 = European Organization for the Research and Treatment of Cancer Quality of Life Questionnaire; EORTC QLQ-PR25 = European Organization for the Research and Treatment of Cancer Quality of Life Questionnaire-Prostate Cancer Module; HRQL $=$ health-related quality of life; MID = minimal important difference; post-CTx $=$ current or post-docetaxel chemotherapy at inclusion. 
Supplemental Table 6 Time to Clinical Relevant Deterioration in Months of HRQ.oL per Disease State

\begin{tabular}{|c|c|c|c|c|c|c|}
\hline & & \multicolumn{2}{|c|}{ CTX-naive $\mathrm{N}=112$} & \multicolumn{2}{|c|}{ Post-CTx N = 39} & \multirow[t]{2}{*}{$P$ Value } \\
\hline & & No. Events, \% & Time to MID, mos & No. Events, \% & Time to MID, mos & \\
\hline $\begin{array}{l}\text { Generic HRQOL (EQ- } \\
\text { 5D) }\end{array}$ & EQ VAS & 56.3 & 12.3 (6-NR) & 69.2 & $10.0(4-21)$ & .299 \\
\hline \multirow{15}{*}{$\begin{array}{l}\text { Cancer-specific } \\
\text { HRQoL (EORTC QLQ- } \\
\text { C30) }\end{array}$} & Global health status & 55.4 & $15.1(7-26)$ & 51.3 & 13.4 (7-NR) & .978 \\
\hline & Physical functioning & 58.9 & $14.7(6-26)$ & 59.0 & 6.8 (4-NR) & .490 \\
\hline & Rolefunctioning & 63.4 & $12.3(5-22)$ & 51.3 & 12.1 (4-NR) & .521 \\
\hline & Emotional functioning & 31.3 & 26.6 (12-NR) & 41.0 & NR (6-NR) & .167 \\
\hline & Cognitive functioning & 52.7 & $12.6(6-28)$ & 56.4 & 10.0 (6-NR) & .847 \\
\hline & Social functioning & 53.6 & 14.2 (9-NR) & 61.5 & 9.5 (6-NR) & .276 \\
\hline & Fatigue & 64.3 & $8.6(4-23)$ & 71.8 & $6.5(4-13)$ & .381 \\
\hline & Nausea/vomiting & 44.6 & 19.9 (9-NR) & 53.8 & $15.3(9-25)$ & .279 \\
\hline & Pain & 52.7 & 15.8 (6-NR) & 66.7 & $10.2(6-24)$ & .200 \\
\hline & Dyspnea & 42.9 & 22.6 (8-NR) & 43.6 & 20.1 (7-NR) & .805 \\
\hline & Insomnia & 43.8 & 21.8 (9-NR) & 33.3 & NR (10-NR) & .356 \\
\hline & Appetite loss & 50.9 & 16.5 (8-NR) & 41.0 & NR (9-NR) & .459 \\
\hline & Constipation & 39.3 & 24.5 (9-NR) & 35.9 & 24.1 (12-NR) & .672 \\
\hline & Diarrhea & 35.7 & NR (10-NR) & 38.5 & 21.7 (8-NR) & .696 \\
\hline & Financial difficulties & 20.5 & NR (24-NR) & 10.3 & NR (NR-NR) & .205 \\
\hline \multirow{6}{*}{$\begin{array}{l}\text { Prostate cancer- } \\
\text { specific HRQoL } \\
\text { (EORTC QLQ-PR25) }\end{array}$} & Sexual activity & 17.0 & NR (NR-NR) & 5.1 & NR (NR-NR) & .092 \\
\hline & Sexual functioning & 2.7 & NR (NR-NR) & 0 & NR (NR-NR) & .353 \\
\hline & Urinary symptoms & 28.6 & 25.6 (15-NR) & 20.5 & NR (19-NR) & .571 \\
\hline & Bowel symptoms & 18.8 & NR (25-NR) & 12.8 & NR (NR-NR) & .783 \\
\hline & Incontinence aid & 5.4 & NR (NR-NR) & 5.1 & NR (NR-NR) & .941 \\
\hline & $\begin{array}{l}\text { Hormonal therapy } \\
\text { related symptoms }\end{array}$ & 26.8 & 26.3 (16-NR) & 30.8 & NR (12-NR) & .242 \\
\hline \multirow[t]{6}{*}{ Pain $(\mathrm{BPI}-\mathrm{SF})^{\mathrm{a}}$} & Pain severity & 32.6 & NR (11-NR) & 40.0 & NR (9-NR) & .408 \\
\hline & Worst pain & 41.9 & 24.5 (8-NR) & 64.0 & $9.9(7-16)$ & .042 \\
\hline & Average pain & 32.6 & NR (11-NR) & 52.0 & 12.5 (10-NR) & .072 \\
\hline & Least pain & 39.5 & NR (10-NR) & 36.0 & NR (11-NR) & .833 \\
\hline & Current pain & 30.2 & NR (11-NR) & 40.0 & NR (9-NR) & .349 \\
\hline & Pain interference & 31.4 & NR (15-NR) & 32.0 & NR (10-NR) & .633 \\
\hline
\end{tabular}

Data are presented as percentages for number of events (ie, number of patients with MID) and median (IQR) for time to first MID.

$P$ values calculated for differences in time to first MID between CTx-naive and post-CTx patients.

Abbreviations: BPI-SF = Brief Pain Inventory-Short Form; CTX-naive = no or no prior docetaxel chemotherapy at inclusion; EORTC QLQ-C30 = European Organization for the Research and Treatment of Cancer Quality of Life Questionnaire; EORTC QLQ-PR25 = European Organization for the Research and Treatment of Cancer Quality of Life Questionnaire-Prostate Cancer Module; HRQoL = healthrelated quality of life; $I Q R=$ interquartile range; $M I D=$ minimal important differences; $N R=$ not reached; post-CTx $=$ current or post-docetaxel chemotherapy at inclusion; $V A S=$ visual analog scale. ${ }^{\mathrm{a} O n l y}$ patients with BPI-SF measurement at inclusion (CTx-naive, $N=86$ and post-CTx, $N=25$ ). 